\title{
The unofficial Economy in Transition
}

\section{Citation}

Johnson, Simon, Daniel Kaufmann, and Andrei Shleifer. 1997. The Unofficial Economy in Transition. Brookings Papers on Economic Activity 1997, no. 2: 159-239.

\section{Published Version}

https://www.brookings.edu/wp-content/

uploads/1997/06/1997b_bpea_johnson_kaufmann_shleifer_goldman_weitzman.pdf

\section{Permanent link}

http://nrs.harvard.edu/urn-3:HUL.InstRepos:30728045

\section{Terms of Use}

This article was downloaded from Harvard University's DASH repository, and is made available under the terms and conditions applicable to Other Posted Material, as set forth at http:// nrs.harvard.edu/urn-3:HUL.InstRepos:dash.current.terms-of-use\#LAA

\section{Share Your Story}

The Harvard community has made this article openly available.

Please share how this access benefits you. Submit a story.

Accessibility 
SIMON JOHNSON

Massachusetts Institute of Technology

DANIEL KA UFMANN

World Bank

ANDREI SHLEIFER

Harvard University

\section{The Unofficial Economy in Transition}

THE ECONOMIES of eastern Europe and the former Soviet Union (FSU) escaped communism with a heavy burden. When central planning collapsed, they continued to suffer from widespread political control of economic activity. Such politicization had to be reduced significantly for small business formation and growth to begin. In recent years, some of these countries have succeeded much better than others in replacing political control with functioning market institutions. As this paper shows, they are also the countries that have had the healthiest public finances, the smallest unofficial economies, and the best records of growth.

The politicization of economic life can usefully be thought of as the exercise by politicians of control rights over business. ${ }^{\prime}$ Such rights may include regulatory powers over privatized and private firms, the ability to regulate and restrict entry, control over the use of land and real estate that private businesses occupy, the determination and collection of taxes

For helpful comments, we thank Olivier Blanchard, Cevdet Denizer, Alan Gelb, Edward Glaeser, Marshall Goldman, Roger Gordon, Oleh Havrylyshyn, Rafael La Porta, Florencio Lopez-de-Silanes, Norman Loayza, Jakob Svensson, Daniel Treisman, Martin Weitzman, and the participants of seminars at Massachusetts Institute of Technology, the Davidson Institute at the University of Michigan, and the World Bank, and of the Brookings Panel meeting. Aleksander Kaliberda, Isztvan Dobozi, and Gerhard Pohl provided generous help with the data. Views expressed in the paper are the authors' responsibility and are not necessarily the views of the institutions with which they are affiliated.

1. Grossman and Hart (1986); Boycko, Shleifer, and Vishny (1995). 
on businesses, the right to inspect firms and close them if regulations are violated, control over international trade and foreign exchange transactions, and in some cases, even the power to set prices. Typically, politicians use these rights to pursue their own interests, such as maintaining employment in certain firms, supporting politically friendly and punishing politically unfriendly entrepreneurs, and subsidizing their allies. ${ }^{2}$ Politicians also use these rights to enrich themselves by offering firms relief from regulation in exchange for bribes. ${ }^{3}$ Political control generally reduces the profitability of doing business, and therefore adversely influences entrepreneurial activity and economic growth. ${ }^{4}$

During the transition from communism to capitalism, the adverse effects of political control on growth are manifested in a number of ways. Most directly, when profits or potential profits are taken away from firms through regulation, taxation, or corruption, entrepreneurs choose not to start firms or expand less rapidly than they might otherwise. But entrepreneurs have another option, namely, to operate unofficially. ${ }^{5}$ In many transition economies, a consequence of politicization has been the growth of the unofficial economy, in which firms can avoid taxes and regulations, though probably not bribes. Firms that operate unofficially use protection and other "public' services supplied by private-including criminal-organizations. In this paper, we show that the politicization of economic life and the resulting reallocation of resources to the unofficial sector have profound effects on both the structure and the growth rate of a transition economy.

Specifically, we show that the movement of production into the unofficial economy has significant consequences for public finance. Since firms in the unofficial sector largely escape taxation, the reallocation of resources into that sector undermines tax collections, and consequently the ability of the government to provide public goods in the official sector. Such public goods include law and order, effective tax and regulatory institutions, and relatively uncorrupt public administration. The lack of provision of such market-supporting public goods makes operating in the official sector even less attractive to firms, and

2. Shleifer and Vishny (1994).

3. Shleifer and Vishny (1993); Kaufmann (1997).

4. De Soto (1989).

5. Kaufmann and Kaliberda (1996); Kaufmann (1997). 
can set off the collapse of public finances as more and more firms escape into the unofficial economy.

Economies find themselves in either of two very different equilibria. In the first, tax distortions and regulations are low, government revenues are high, the provision of public goods in the official sector is sufficient, and therefore the unofficial sector is small. In the second equilibrium, in the official sector taxes and regulations are prohibitive, public finances are precarious, public goods provision is inadequate, and as a consequence, much of the economic activity is concentrated in the unofficial sector. If firms are more productive in the official than in the unofficial sector, the second equilibrium is associated with worse aggregate performance than the first.

Our work can be thought of as complementing Olivier Blanchard's analysis of transition economies, which highlights the creation of new private firms by entrepreneurs as the engine of growth. ${ }^{6}$ We focus on the political and institutional determinants of the entrepreneurial response, and in particular, on the allocation of resources between the official and the unofficial sectors. We are not the first to stress the role of depoliticization in transition or the importance of building marketsupporting rather than market-distorting institutions. ${ }^{7}$ In this tradition, our paper focuses on the implications of excessive regulation and taxation for the government's budget and for the provision of public goods required by a market economy.

Empirical analysis of the determinants of growth in transition economies has largely focused on the effects of stabilization. ${ }^{8}$ Several of these studies also recognize the importance of depoliticization and institution-building for the efficiency of the economy, and therefore for growth. ${ }^{9}$ We elaborate on the existing literature in three distinct ways.

First, we describe the role of the unofficial economy in transition

6. Blanchard (1997).

7. See Frydman and Rapaczynski (1991), Shleifer and Vishny (1994), Boycko, Shleifer, and Vishny (1995, 1996), Kaufmann and Siegelbaum (1997), and Shleifer (1997a, 1997b).

8. See Sachs (1995), Åslund, Boone, and Johnson (1996), Fischer, Sahay, and Végh (1996b), de Melo, Denizer, and Gelb (1996), and Sachs and Warner (1996).

9. In an important extension of work done at the World Bank, de Melo and others (1997) argue that initial conditions had a significant impact on the choice of reform policies. They include some proxies for institutions, and look at whether a country was independent before 1989 and whether it had "market memory.," 
and measure its size. ${ }^{10}$ The unofficial economy does not receive enough attention in recent studies of reform. Neither the World Bank, nor the European Bank for Reconstruction and Development (EBRD), nor the International Monetary Fund (IMF) offers systematic estimates of the unofficial economy. ${ }^{11}$ Norman Loayza presents an early theoretical analysis of the unofficial economy and applies it to the analysis of the Latin American experience. ${ }^{12}$ Loayza does not measure the unofficial economy, as we do below.

Second, we emphasize the public finance aspects of transition by focusing our empirical analysis on the consequences for the government's budget of the escape of new firms from the official economy, and on the provision of potentially beneficial public goods. ${ }^{13}$ Law and order is one key public good that can be measured empirically in transition economies, but we are more broadly interested in the financing of a range of market-supporting institutions, including regulatory agencies, a reasonably honest public administration, and so forth. We look at the relationship between taxes and regulations, government budgets, and the provision of public goods, and examine the consequences of the condition of public finances for both the unofficial economy and economic growth. ${ }^{14}$

Third, we revisit the evidence on the beneficial effects of stabilization on growth. Since most countries that stabilized early have also implemented widespread deregulation, it is difficult to ascertain from the available data whether stabilization by itself has a direct benefit for growth by itself, or needs to be combined with other elements of de-

10. See also Kaufmann (1994); Kaufmann and Kaliberda (1996).

11. See World Development Report (World Bank, 1996b); Transition Report (European Bank for Reconstruction and Development, 1995, 1996); and for the IMF, Citrin (1995) and Fischer, Sahay, and Végh (1996a, 1996b). Leitzel (1995) analyzes changes in the character of unofficial activities in Russia as a result of reform. EBRD (1995, annex 2.1) contains estimates of the "hidden economy," based on surveys in Hungary, Estonia, Slovenia, Bulgaria, and Romania, although it is not clear whether the same methodology was used in all countries.

12. Loayza (1996).

13. Sachs (1995) considers some of the related public finance and public good provision issues in his analysis of the Russian stabilization.

14. Brunetti, Kisunko, and Weder (1997) present cross-country measures of institutions (aggregated by region), which broadly confirm our findings. They report that these institutional variables have a significant effect on measures of official per capita income. 
politicization and institution-building. The positive effects on entrepreneurship of stabilization and liberalization combined are now well established. ${ }^{15}$ However, recent evidence-in particular, from Russia, where, in contrast with eastern Europe, stabilization has advanced ahead of depoliticization-suggests that stabilization is at best not the whole story behind growth. ${ }^{16}$ Our analysis suggests that stabilization may, indeed, not be sufficient for the resumption of growth, and that the building of market-supporting institutions is a separate and crucial requirement of a successful transition. The EBRD's 1997 Transition Report takes this point of view as well.

In the next three sections of the paper we present a simple model, describe our data, and present the evidence on the effects of political control on the unofficial economy. The following section focuses on the determinants of growth. The next section revisits the data on stabilization. The paper concludes with a discussion of the reform agenda of countries in the former Soviet Union, as suggested by our empirical findings.

\section{A Simple Model}

Our model captures, in the starkest way, some of the ideas described above. We consider the allocation of labor between the official and the unofficial sectors of the economy. The government imposes taxes on the official sector and provides public goods from the tax revenues. These public goods, such as law and order, increase the productivity of firms in the official sector. The unofficial sector does not pay official taxes, but neither does it have access to the public goods provided by the government. Instead, it pays fees to private protection agencies to provide some public goods, such as protection from thieves and contract enforcement. ${ }^{17}$ The quality of that protection depends on the revenues

15. For a formal discussion of optimal reform in the presence of complementarities (for example, between stabilization and liberalization), see Johnson and Loveman (1995), Friedman and Johnson (1996), and World Bank (1996b).

16. See Frye and Shleifer (1997) and Shleifer (1997b) for a comparison of Russia and Poland along these lines, and Kaufmann (1997) for a comparison of Russia and Ukraine.

17. A more elaborate version of this model would allow public officials to "privately" provide protection from excessive regulatory and tax harassment, in exchange for bribes. 
raised by the private agencies. We examine the allocation of labor between the two sectors and its implications for tax revenues, law and order, and the efficiency of the economy.

Denote by $t$ the generalized tax rate on output in the official sector. The generalized tax rate includes taxation, regulation, and corruption (that is, bribes). Taxes raise revenue for the government, but some of the generalized taxes, such as regulation and bribes, do not. For now, let $t$ be the share of output that the government in various ways removes from each firm in the official sector and obtains for its budget. Let $s$ denote the corresponding generalized tax rate in the unofficial sector, charged by the private enforcers of law and order, to whom we loosely refer as the mafia. Analogous to the official sector, collections from $s$ enter the mafia's budget.

Let $T$ be the tax revenue in the official sector, and $S$ the tax revenue in the unofficial sector. Let $Q$ be the quantity of the public good, such as law and order, in the official sector, and $R$ be the corresponding quantity in the unofficial sector. Here $Q$ captures the public goods from which firms operating unofficially can be excluded. For instance, firms in the unofficial sector do not have access to police, courts, or administrative assistance from the government. In contrast, such public services as roads, healthcare, and education are accessible to all firms, even those in the unofficial sector, and hence $Q$ does not properly capture these goods.

Let $L$ be the aggregate labor force, and let the wage rate be normalized to 1 . Finally, let $F$ and $I$ be the subscripts denoting the official and the unofficial sectors, respectively; so that $L_{F}$ and $L_{I}$ denote the labor employed, $\Pi_{F}$ and $\Pi_{I}$ the after-tax profits, and $Y_{F}$ and $Y_{I}$ the output in each sector.

Consider the official sector first. The production function is assumed to be given by

$$
Y_{F}=Q L_{F},
$$

so that the quantity of the public good directly enhances the productivity of the official sector. As a consequence, after-tax profits are given by

$$
\Pi_{F}=(1-t) Q L_{F}-L_{F} .
$$

The tax revenue, $T$, is given by $T=t Q L_{F}$. We assume that the supply of public goods is increasing and concave in tax revenue; that is, $Q=$ 
$Q(T)$, with $Q^{\prime}>0$ and $Q^{\prime \prime}<0$. This does not mean that government resources are spent entirely on the provision of public goods; indeed, a large portion might be stolen or wasted. We only assume that at least some share of the marginal dollar is spent on public goods.

This assumption raises an important substantive point, namely, that the cost of providing market-supporting public institutions may be so low that even a nearly bankrupt government could afford an adequate level of provision. Our assumption that a decline in government revenue leads to a deterioration in the supply of public goods may, therefore, miss the mark. Indeed, in the Russian federal budget for 1995, only about 10 percent of the expenditure was, by its own definition, dedicated to "law and order.' Nevertheless, we believe that our assumption is appropriate because, despite their enormous benefits, marketsupporting public goods are often among the first to be cut in a transition economy when the budget deteriorates. In such a situation, the government is typically weak, disorganized, and torn in a variety of directions by powerful lobbies who apply pressure to maintain the level of much less socially useful expenditures, such as agricultural and industrial subsidies and defense spending. In contrast, expenditures on the essential and more purely public goods, such as law and order, science, healthcare, and education, suffer.

Importantly, we also assume that the government does not spend any of its tax revenue to fight the mafia or to restrict the movement of firms into the unofficial sector. The government and the mafia compete for business - and therefore for the revenue base - through the combinations of tax rates and public goods that they offer in their respective sectors.

From the government's budget constraint, one obtains $Q=Q\left(t Q L_{F}\right)$. Eliminating $Q$ from the right-hand side, we write $Q=q\left(t L_{F}\right)$. For $q$ expressed only as a function of $t L_{F}$, it is easy to verify that $q^{\prime}>0$ and, in some cases, $q^{\prime \prime}>0$. This is the first possible increasing return in our model: as public good provision increases, so does the productivity of the private sector and the tax revenues that it furnishes, which finances a further increase in public good provision. The $q$ function exhibits increasing returns if the government is sufficiently productive at converting revenues into public goods. For example, if $Q(T)=T^{\alpha}$ and $\alpha>1 / 2$, then $q^{\prime \prime}>0$.

One can repeat the above line of reasoning for the mafia, which 
Figure 1. The Unofficial Economy and the Collapse of Public Finances

Tax revenue and public goods $(T$ and $Q$ )

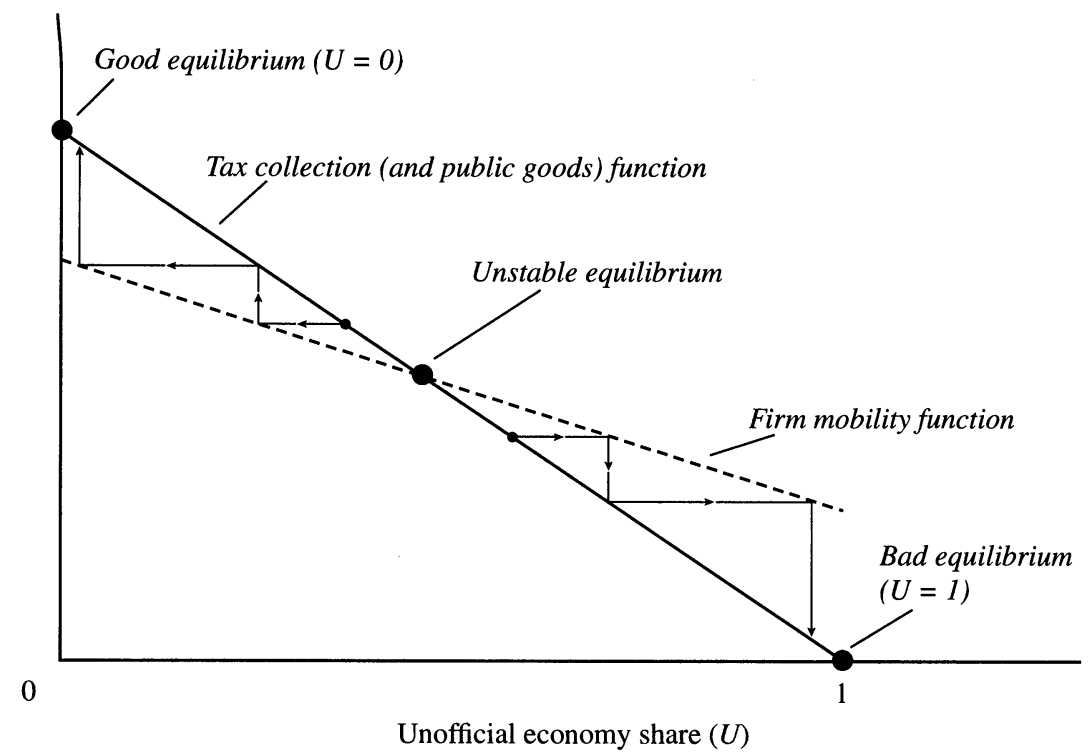

Source: Authors' model, as described in text.

collects taxes from firms in the unofficial sector and produces public goods for the firms it protects. For the unofficial sector, $R=r\left(s L_{l}\right)$, where $r^{\prime}>0$ and, under some conditions, $r^{\prime \prime}>0$. We do not, however, focus on these particular increasing returns in either the official or the unofficial sector because it seems implausible that the marginal expenditure from the budget on market-supporting public institutions is so high.

Figure 1 presents the equilibria in the model. In equilibrium, the labor market clears, so that $L_{I}+L_{F}=L$. The figure graphs the tax revenue and quality of public goods against the share of the unofficial economy. The solid line shows that the higher is the share of the unofficial economy, the lower are the official tax collections, and hence the supply of public goods to the official sector. The dotted line-the firm mobility function-shows that the higher is the supply of public goods in the official economy, the fewer firms choose to operate unofficially. The dotted line generally cuts the solid line from below. 
In general, there are three equilibria in this model: one in which all resources are concentrated in the official sector, one in which all resources are in the unofficial sector, and a knife-edge equilibrium in which the two sectors coexist. The existence of the extreme equilibria is independent of the possible convexity of the $q$ and $r$ functions; that is, there is a second, and totally separate, source of increasing returns to sector size.

When all resources are concentrated in the unofficial sector, government tax collections in the official sector are zero, hence so is the amount of the public good supplied in that sector, as well as its productivity. As a consequence, all firms choose to stay in the unofficial sector. This equilibrium is stable. When nearly all firms are in the unofficial sector, government revenues do not suffice to provide the level of public goods needed to draw firms back into the official sector; in fact, more resources move to the unofficial sector. In figure 1, this equilibrium is stable because the dotted line is above the solid line when all, or nearly all, of the resources are in the unofficial sector.

Similarly, if all resources are concentrated in the official sector, the tax revenues and public good provision in that sector are high enough that all firms choose to stay there. The equilibrium is stable because when only a few firms are operating unofficially, it is to the advantage of these firms to switch back and receive the public goods of the official sector. In figure 1, the dotted line is below the solid line when the size of the unofficial sector is near zero. The forces causing the multiplicity of equilibria in this model are general, and are closely related to the idea of fiscal increasing returns of Blanchard and Lawrence Summers, even though more realistic specifications would generate less extreme outcomes. ${ }^{18}$

To examine the intermediate equilibrium, we compute the profits of the marginal firm, which is indifferent to being in the official or the unofficial sector. This firm takes aggregate employment in the two sectors, $L_{F}$ and $L_{l}$, as given. Its marginal profit in the official sector is given by $(1-t) q\left(t L_{F}\right)-1$, and its marginal profit in the unofficial sector is $(1-s) r\left(s L_{l}\right)-1$. In equilibrium, it must be that

18. Blanchard and Summers (1987) present a model in which an increase in government spending reduces unemployment, raises the level of economic activity, and may recover more in increased tax revenues than the government has spent in the first place. 


$$
(1-t) q\left(t L_{F}\right)=(1-s) r\left(s L_{l}\right) .
$$

For a given set of tax rates $t$ and $s$, there generally exist $L_{F}$ and $L_{I}$ adding up to $L$ that solve equation 3 . However, this equilibrium is unstable. If, starting from this equilibrium, a firm tips over from the unofficial to the official sector, the resources of the official sector rise, hence so do tax collections and the quantity of public goods supplied and, finally, the productivity in that sector. More firms then switch into the official sector, and the intermediate equilibrium breaks down.

Although we have presented a static model, it can be given the "cobweb" dynamic interpretation suggested by the arrows in figure 1 . Suppose that an economy-perhaps for historical reasons or because of a good budget shock-ends up on the good side of the intermediate equilibrium, that is, at a point where the unofficial economy is relatively small and tax revenues are relatively large. Firms that are operating unofficially then recognize that the combination of taxes and public goods in the official sector is attractive enough for them to switch. As they move, tax revenues in the official sector rise, and hence so does the provision of public goods in that sector. As this happens, more firms operating unofficially switch, and so on, until this virtuous cycle leads to a fully official economy. Conversely, suppose that an economy ends up on the bad side of the intermediate equilibrium, with a relatively large unofficial economy and low tax revenues. Firms operating officially then recognize that they are better off in the unofficial sector and move. Their move has a deleterious effect on the budget and the provision of public goods in the official sector, which causes more firms to switch to the unofficial economy. This vicious cycle ends up at the extreme equilibrium where the whole economy is unofficial. ${ }^{19}$

To interpret this model and its predictions, it is useful to think of an augmented framework in which, for reasons outside the model, some firms choose to operate in the official sector (for example, state firms or firms dealing extensively with the state) and others choose to operate in the unofficial sector (for example, firms that infringe on patents). In this case, the forces that we describe still operate, but both sec-

19. Costs of congestion in the unofficial sector, suggested by Loayza (1996), put a lower limit on the proportion of the economy that remains official. Evidence suggests that in the former Soviet Union this limit is low and has not yet been reached (see below). 
tors coexist in equilibrium. What does the analysis say about such situations?

The key prediction of the model is the potential separation of economies into two distinct groups. In one, the government offers a sufficiently attractive combination of tax rates, regulations, and public goods that most firms choose to stay in the official sector. In this group, government revenues suffice to provide the public goods, and the unofficial sector is small because the government outcompetes it. In the other group, the government does not offer firms a sufficiently attractive combination of tax rates, regulations, and public goods to keep them operating officially, and hence many of them end up in the large unofficial sector, which offers a more attractive combination. The government budget in these countries does not suffice to offer more public goods, and hence the unofficial sector wins the competition for firms.

Our model does not make any immediate predictions as to which equilibrium is associated with higher output. However, if one makes the auxiliary but plausible assumption that the official sector is more productive at generating public goods, then the overall performance of economies with a small unofficial sector is superior. There are several reasons why the government may be more efficient at converting revenue into public goods: there are increasing returns to the production of some goods, such as defense and laws; the government already has some expertise at producing some of these goods; private providers might not be able to commit credibly to long-term delivery of some services.

These are the very stylized predictions of a very stylized model. We evaluate these predictions empirically in the following sections. But first, we revisit some of the key assumptions responsible for these results, in order to shed light on the theoretical generality of the conclusions.

\section{Taxation, Regulation, and Corruption}

The results are driven by the assumption that excessive taxes force firms out of the official sector. Taxation itself, however, has an offsetting benefit. At least on the increasing part of the Laffer curve, higher taxes raise more money for the government, some of which is spent on public goods. This is not the case with generalized "regulatory" taxes. 
These are more detrimental to the official sector than high taxes proper, since they bring all the distortionary effects but no government revenue. If we included regulation in the model, the tendency toward bifurcation would be even stronger than it is now. In the empirical work, we consider both taxation and regulation.

The effects of corruption are somewhat different from those of taxation and regulation. Entrepreneurs generally pay bribes precisely to avoid paying taxes or following regulations, and therefore corruption reflects payments to evade government control. In general, the higher the level of taxation and regulation $(t)$, the greater are the bribes that politicians can extract from entrepreneurs in return for excusing them from paying taxes or following regulations. Tax and regulatory burdens are therefore highly correlated with the level of corruption, which, in turn, can serve as a proxy for $t$. Similar to regulation, however, corruption does not raise any revenues for the government.

\section{Who Sets Tax Rates?}

In the model, we do not set up decision problems for the government and the mafia, and we treat the tax rates $t$ and $s$ as parameters. The choice of these parameters depends on the nature of competition between the government and the mafia, as well as the nature of competition inside the government (for example, between different levels) and inside the mafia (for example, between competing groups). If the government has access to a superior technology for producing public goods, it can always outcompete the mafia as long as it can set $t$ equal to $s$. The mafia may be at a further disadvantage if competing private gangs independently attempt to impose taxes on the same businesses, if the mafia cannot commit not to expropriate capital ex post, or if it cannot establish a reputation for the consistent provision of public goods such as contract enforcement. The government can also destroy the mafia, a point to which we return below. In short, the government has many advantages, which lead to its victory in most well-functioning economies.

In transition economies, it is less obvious that the government can always offer a better deal. First, the government often spends a lot of its revenues on activities other than the provision of public goods, such as subsidies to various unproductive activities or transfer payments. As 
a result, it might have a bigger leakage than the mafia. Second, the government might, for socially efficient reasons, choose to regulate more than the mafia does-for example, in regard to nuclear safety, pollution, or other externalities. Third, and perhaps most important, governments in some transition economies are disorganized and not in control of themselves. Consequently, $t$ is not set by one unified government, but by a collection of agencies and levels of government that impose taxes, bribes, and regulations largely independent of each other. ${ }^{20}$ In this way, tax distortion in transition economies can be a lot higher than is optimal, which significantly undermines the government's tax revenues, and hence its ability to supply public goods. Moreover, to the extent that the mafia sets $s$ in response to an excessive level of $t$, the mafia can adjust to outcompete the government, for example, by setting $s$ much lower than $t$. The bad equilibrium, then, is a real possibility.

\section{Government Does Not Restrict the Movement of Firms}

A key assumption in our model is that entrepreneurs are free to switch resources from the official to the unofficial sector in seeking a better mix of taxes and public goods. But the government may be able to use political repression to punish anyone who leaves the official sector. It could use tax revenue to fight the mafia or, through raids and expropriation, it could directly penalize firms that are operating unofficially. Similarly, if the government is itself indistinguishable from the mafia, it may be able to impose high marginal taxes on both official and unofficial activities. A government that established itself as a successful repressive monopolist would charge high taxes, collect substantial revenues, and yet provide few public goods, instead using the revenues to line its own pockets and to fuel the machinery of repression. Although we do not model these possibilities explicitly, Belarus and Uzbekistan, both highly repressive states, appear to be outliers in the data. The evidence on Belarus and Uzbekistan is consistent with the model of a repressive monopoly government that collects a lot of taxes but produces few public goods.

20. See Shleifer and Vishny (1993). 


\section{Labor Supply}

One final assumption that warrants comment is that of fixed labor supply. In our model, entrepreneurs move between sectors in search of the best combination of taxes and public goods. Another response to poor government performance is not to produce at all, or to produce in the household sector, which uses no public goods and pays no taxes to either the government or the mafia. The introduction of elastic labor supply would strengthen our conclusion about the bifurcation of economies, because a government offering an unattractive combination of taxes and public goods would see its tax base further eroded by the withdrawal of labor supply. The introduction of elastic labor supply would also substantially strengthen our predictions concerning growth, since bad combinations of taxes and public goods would now lead not only to the reallocation of labor between the official and unofficial economy, but to a first order reduction in output, as labor supply is reduced.

\section{Summary}

Broadly interpreted, our model has a number of empirical predictions. It suggests that in economies where firms are free to move between the official and unofficial sectors, transition is likely to follow one of two paths. Some countries would be characterized by low burdens from taxes, regulation, and corruption; relatively high tax revenues; large quantities of public goods provided by the government; small unofficial sectors; and presumably - if the official sector is more efficient-high growth rates. Other countries would be characterized by high burdens from taxes, regulation, and corruption; low tax collections; small quantities of public goods provided by the government; large unofficial sectors; and presumably, low growth rates. The adverse effect of low $Q$ falls primarily on growth in the official sector.

In our empirical work, we try to obtain some estimates of $t$ and $Q$, as well as of the size of the official and unofficial sectors. Next, we examine the relationship between $t$ and $Q$, on the one hand, and the size of the unofficial sector, on the other. We also examine the validity of the public finance mechanisms operating in our model; that is, the relationship between the tax and regulatory burden $(t)$, the budget $(T)$, and the supply of public goods $(Q)$. We then evaluate the model's 
implications for the growth of the official sector and of the economy overall.

\section{Data}

In this section we discuss our data sources and explain how we use the available information to develop the measures of the unofficial economy and the indicators of reforms.

\section{The Unofficial Economy}

As used here, the "unofficial economy" constitutes activity that is not reported to the state statistical office. For obvious reasons, it is almost never reported to the tax authorities. While our model refers to firms moving between the official and the unofficial sectors, in reality many firms operate in both sectors. An officially registered enterprise might produce and sell some of its output unofficially. It would thus avoid paying taxes and escape regulations related to the production of this output, but at the same time would not be able to rely on the government to enforce related contracts. Indeed, with respect to this unofficial output, the enterprise might pay bribes rather than taxes and hire private protection agencies to help with the contracts. In this way, the official and unofficial sectors are represented within a single firm, and not just across firms.

In the previously communist countries, published GDP figures rarely capture any of this unofficial activity. The EBRD has produced estimates of the unofficial economy for particular countries, but its numbers for different countries are not comparable. ${ }^{21} \mathrm{We}$ are not aware of any other source that offers reliable cross-country estimates for the unofficial economy. Individual government statistical offices provide some numbers, but these too are hard to compare across countries. ${ }^{22}$

We use data on total electricity consumption to compare unofficial

21. EBRD (1995, annex 2.1).

22. For example, for 1996 Russia's Central Statistical Office, Goskomstat, estimates the unofficial economy to have been about 20 percent of total activity. For a critique of their methodology, see Russia's European Centre for Economic Policy, Russian Economic Trends, March monthly update, 1997, as well as Åslund, Boone, and Johnson (1996, p. 257). 
activity across countries ${ }^{23}$ Electricity consumption offers a rough measure of overall economic activity; around the world, the short-run electricity-to-GDP elasticity is usually close to 1 . Measured GDP, by definition, captures only the official part of the economy, so the difference between overall and measured GDP gives an estimate of the size of the unofficial economy.

Assuming a unit output elasticity may underestimate overall GDP and the size of the unofficial economy. First, there is some improvement in the efficiency of electricity use over time, particularly given the very low initial efficiency. Second, higher electricity prices reduce consumption per unit of output. Third, there may be a shift of the output mix away from electricity-intensive industries, both within existing enterprises and in the creation of new businesses, especially in services. Fourth, the underreporting of electricity consumption may increase, although the amount of electricity stolen is small and probably does not vary over time. However, a unit elasticity assumption would overestimate the overall size of a declining economy if electricity is used primarily for "overhead" activities, such as lighting buildings. Energy efficiency may also worsen due to neglect of essential maintenance and some substitution of electricity for other energy sources (for example, switching from gas to electric heating). On balance, the unit elasticity assumption probably leads to only a small underestimate of total economic activity, particularly where there has been a significant adjustment in the relative price of electricity. ${ }^{24}$

Drawing on the work of Dale Gray, Caroline Freund and Christine Wallich, and discussions with other World Bank energy experts, Kaufmann and Aleksander Kaliberda develop a simple tiered classification of ex post output elasticity for electricity consumption. ${ }^{25}$ The " energy efficient" economies - the central and eastern European countries, where energy price adjustments started earlier and have been more

23. We use total-rather than just industrial-electricity consumption because new private sector activities probably use "nonindustrial" electricity; for example, when service sector firms operate out of apartments.

24. Gray (1995) reports that electricity prices for industry in 1994 were 5.2 cents per kilowatt hour in Hungary and 5.6 cents in the Czech Republic, but only 2.7 cents in Russia and 1.4 cents in Ukraine. In addition, there is strong anecdotal evidence that payment arrears to electricity suppliers are much higher in the former Soviet Union than in eastern Europe.

25. Gray (1995); Freund and Wallich (1995); Kaufmann and Kaliberda (1996). 
significant-are assumed to have an output elasticity of electricity consumption of 0.9 when their economies begin to grow again. The "energy neutral" economies - the Baltic countries, where price adjustment has taken place but started later-are assumed to have a unitary elasticity of electricity consumption. The "energy inefficient" economies - the rest of the former Soviet Union, where price adjustments started relatively late and have been much smaller-are assumed to have an output elasticity of electricity consumption of $1.15 .{ }^{26}$ Relative to the unit elasticity assumption, these assumptions tend to reduce our estimate of the unofficial economy for the former Soviet Union and to raise it for eastern Europe. In particular, they address the concern that because eastern Europe has experienced much more rapid growth in services than the FSU, and services are not as electricity intensive as manufacturing, the estimates of the unofficial economy under the unit elasticity assumption would be biased upward for the FSU and downward for eastern Europe. We have rerun our regressions using the unit elasticity assumption but have not found any notable differences. The regressions and figures presented below use electricity consumption data for 1995. We have also confirmed our results using 1994 data.

The difference between the change in electricity consumption and that in official GDP yields an estimate of the change in the size of the unofficial economy. To calculate the growth of the unofficial economy, one needs to have an estimate of its initial (prereform) size. We use the estimates cited by Kaufmann and Kaliberda, based on various studies, suggesting the following shares of unofficial activity in total activity for 1989: Bulgaria, 22.8 percent; Czech Republic and Slovakia, 6.0 percent; Hungary, 27.0 percent; Poland, 15.7 percent; Romania, 22.3 percent; and all the former Soviet republics, 12.0 percent. ${ }^{27}$ The fact that the share of the unofficial economy in the formerly Soviet countries is relatively low is probably due to much greater state repression of such activity in the FSU. The Czech Republic and Slovakia were also

26. The elasticity is usually not the same when output is falling and when it is rising. Assuming an elasticity of 1.15 for the relationship between energy consumption and output when output is increasing (because energy use is becoming less efficient) is equivalent to assuming an elasticity of 0.87 (the inverse of 1.15) when output is falling. Similarly, the assumption of an elasticity of 0.9 for central and eastern Europe when output is increasing (due to an improvement in energy efficiency) is equivalent to an elasticity of 1.11 when output is falling.

27. Kaufmann and Kaliberda (1996). 
highly repressed under communism and also have a low initial share of the unofficial economy.

In addition to estimating the size of the unofficial economy, we calculate the level of total GDP-official plus unofficial GDP. ${ }^{28} \mathrm{We}$ use this to examine the effect of policies on the total level of output and to check the robustness of the results obtained by using official GDP as the dependent variable.

There are twenty-five "transition economies" (as listed in appendix D), but we are able to use electricity data for only seventeen: Bulgaria, the Czech Republic, Hungary, Poland, Romania, and the Slovak Republic in central and eastern Europe; Estonia, Latvia, and Lithuania in the Baltics; Russia, Ukraine, Moldova, and Belarus in the western part of the former Soviet Union; Azerbaijan and Georgia in the Caucasus; and Uzbekistan and Kazakhstan in Central Asia. We have data for Armenia and Kyrgystan, but have been informed by World Bank economists that there is no stable relationship between electricity consumption and output in these countries, due to enormous disruptions in electricity generation in Armenia and to large shifts toward electricity consumption in Kyrgystan. We could not obtain enough information for the other transition countries.

\section{Measures of Reform}

In examining the effects of political control on economic performance, we divide measures of policy into two categories. In the first category are proxies for $t$ in our model, including measures of general liberalization, external liberalization (as a proxy for deregulation of foreign trade), privatization, deregulation, and the fairness of taxation. ${ }^{29}$ We also use corruption as a measure of $t$, since, as indicated above, they should be highly correlated.

The second category includes direct measures of public goods in the official sector, $Q$. In particular, we focus on the legal environment in different countries, since this is an area in which firms in the official

28. These numbers for total GDP do not rely on our estimates of the "initial" unofficial economy, but are derived by assuming that changes in electricity consumption equal changes in total GDP, applying the elasticity correction described in the text.

29. In some models, such as Shleifer and Vishny (1994), privatization is directly linked to the reduction of government control. 
sector derive the benefits of government services to a much greater extent than do firms in the unofficial sector.

International organizations have attempted to measure $t$ and $Q$ for postcommunist economies. We use a variety of sources that evaluate reform from different perspectives. Here we briefly introduce the variables; more detail is provided in appendix A.

Based on discussions with World Bank country economists, Martha de Melo, Cevdet Denizer, and Alan Gelb develop measures of internal liberalization, external liberalization, and private sector development. ${ }^{30}$ They provide both a score for each year and an overall "cumulative liberalization index," which is the sum of all liberalization scores since 1989. Since the World Bank index of internal liberalization is the best available measure of the extent to which prices are still subject to government control, we use it below. We rely on other sources to measure the extent of external liberalization and privatization. ${ }^{31}$

The European Bank for Reconstruction and Development offers ten measures of liberalization, grouped into five categories: (1) private sector share of GDP; (2) large-scale privatization, small-scale privatization, and enterprise restructuring; (3) price liberalization, trade and foreign exchange system, and competition policy; (4) banking reform and interest rate liberalization, and securities markets and nonbank financial institutions; and (5) extensiveness and effectiveness of legal rules on investment. ${ }^{32}$ Each country is given one of five scores, from 1 to $4^{*}$, where a higher score indicates more reform and $4^{*}$ effectively equals 5 .

Of these measures, we use large-scale privatization, trade and foreign exchange system (external liberalization), extensiveness of legal rules, and effectiveness of legal rules in the regressions reported below. When we estimated regressions with "small-scale privatization," the results were similar to those obtained with large-scale privatization. The enterprise restructuring variable is rather vaguely defined and almost all countries get a score of either 2 or 3 . Similarly, price liberal-

30. De Melo, Denizer, and Gelb (1996).

31. De Melo, Denizer, and Gelb's indexes for external liberalization and privatization, however, give very similar results to those presented below.

32. European Bank for Reconstruction and Development $(1995,1996)$. Scores on the extent and effectiveness of legal rules on investment are provided together, under "legal reform," in the summary table (1995, table 6.1, p. 103), but separately in a subsequent table (1996, box 2.1). 
ization is defined in such a way that all countries (except Turkmenistan) score 3 in 1995. For this reason, we prefer the World Bank index described above. The competition policy and financial institutions measures are not directly relevant to this paper.

We rely on the International Monetary Fund for data on the budget deficit as a percentage of GDP and log inflation. ${ }^{33}$ We have obtained updated data that we understand to represent the latest official IMF estimates through the end of $1996 .{ }^{34}$ We use official GDP data from the World Bank.

In addition to data provided by these international organizations, we use several independent assessments of the extent and nature of reform. For three years, 1995-97, the Central European Economic Review $(C E E R)$, published as a supplement to the Wall Street Journal Europe, has asked a panel of western experts, primarily from the investment community, to rate reform in transition economies on various dimensions. ${ }^{35}$ Each year's panel is different, as are the questions that it is asked. We look at the four measures that are relevant to our discussion: legal safeguards, crime and corruption, and the tax fairness index (from the 1996 issue); and rule of law (from 1997). For more detail on these ratings, see appendix $B$.

The tax fairness index is particularly important for the analysis that follows. It is designed to reflect both rates of taxation and fairness of administration. Conceptually, this is the proper approach. In terms of posted rates of taxation, Russia and other countries of the former Soviet Union are not much different from most of eastern Europe.$^{36}$ However,

33. Results using earlier versions of these data have been published in Fischer, Sahay, and Végh (1996b). We have looked at additional measures of inflation and budget performance, available from the EBRD and the World Bank's Office of the Chief Economist. The IMF appears to have the best series, both in terms of comparability across countries and in terms of being revised to reflect retrospective reevaluations by country statistical offices and by the IMF. We do note, however, that there are at least two different estimates of budget deficits for the former Soviet countries within the IMF itself; see Cheasty and Davis (1996) and Fischer, Sahay, and Végh (1996a, 1996b).

Note, also, that inflation is used in logs to avoid distortion of the results due to Georgia's very high inflation in 1994 and 1995.

34. Ratna Sahay, International Monetary Fund, personal communication, November 1996.

35. “Through a Glass Darkly," Central European Economic Review, February 1995, pp. 8-9; “'The Great Growth Race,' CEER, December 1995-January 1996, pp. 8-9, 13; “'Continental Divide,' CEER, December 1996-January 1997, pp. 10-11, 27.

36. European Bank for Reconstruction and Development $(1995,1996)$. There are 
it appears that tax administration is a good deal more capricious in the FSU, with different parts of government collecting taxes arbitrarily. The CEER panel deems that this leads to lower scores on tax fairness (or a higher "tax burden") in the FSU. ${ }^{37}$

The Heritage Foundation scores almost every country in the world on ten measures of "economic freedom": trade policy, taxation policy, government consumption of economic output, monetary policy, capital flows and foreign investment, banking policy, wage and price controls, property rights, regulation, and the black market. ${ }^{38}$ The ratings on regulation, the variable of most interest to us, are somewhat idiosyncratic. For example, in 1996 Poland, Russia, and Belarus all get a score of 2 , which seems quite unreasonable-especially because the criteria for this score include "no bribes," which anecdotal and survey evidence clearly contradict for each of these countries. ${ }^{39}$ As implausible, the Czech Republic gets a perfect 4 . We use this index with caution. We use the 1996 ratings (primarily reporting on 1995), which cover twenty transition countries, including fifteen of the seventeen for which we have reliable electricity data (that is, excepting Kazakhstan and Uzbekistan). Comparing these 1996 ratings with economic performance data from 1995 is not likely to create a large bias.

Freedom House measures political freedom around the world in its "Comparative Survey of Freedom,", which "does not rate governments per se but rather the rights and freedoms individuals have in each country and territory." 40 Countries are assessed both on "political rights [which] enable people to participate freely in the political process

no significant results in our regressions if we use the EBRD's measure of corporate tax rates (EBRD, 1996, annex 2.2). The posted rates are too similar across countries.

37. "We asked our panel to rank each of the twenty-six countries on the basis of their attractiveness as a place to do business over the coming year. Grades were given on a scale of 0 to 10 with 0 the lowest and 10 the highest score." ("The Great Growth Race,' Central European Economic Review, December 1995-January 1996, p. 9) One of the categories is "tax burden." Although tax rates are relatively similar across countries, the scores for this variable vary widely. Our interpretation is that the experts were taking into account both tax rates and the fairness of tax administration.

38. Johnson and Sheehy (1996, chap. 3). To facilitate comparison with measures of reform from other sources, we rescale their variables by multiplying by $(-1)$ and adding 5 , so that each index runs from 0 to 4 , where a higher score is better.

39. See Frye and Shleifer (1997) and Kaufmann (1997).

40. Freedom House, "The Comparative Survey of Freedom 1995-96," available on the Freedom House worldwide web page. Data used in this paper were downloaded January 2, 1997. 
... the system by which the polity chooses the authoritative policy makers and attempts to make binding decisions affecting the national, regional, or local community," and on "civil liberties [which] are the freedoms to develop views, institutions and personal autonomy apart from the state." Each is rated on a seven-point scale, with 1 being the most free and 7 the least free ${ }^{41}$ We rescale their variable by multiplying by $(-1)$ and adding 7 , so that a higher score is better. Freedom House ratings are always reported for two years-for example, 1995-96-but our interpretation is that they pertain primarily to the first year of the pair, so we assign the 1995-96 score to 1995 .

In 1997, Freedom House published new measures of political reform for postcommunist countries. ${ }^{42}$ These include assessments of "political process" and "civil society," which appear to be very close to their previous measures of political rights and civil liberties. In addition, however, they assess "independent media," "rule of law," and "'government and public administration." Again, we rescale all indexes from 0 to 6 , with 6 representing the highest level of achievement.

On the whole, experts agree in their rankings of the extent of reform. ${ }^{43}$ Appendix C illustrates the similarity of rankings, giving a detailed comparison for alternative ratings of the legal environment in the former Soviet Union. None of our main results is sensitive to the choice of index.

\section{Control Variables}

Undoubtedly, there are important structural differences between central and eastern Europe and the former Soviet Union that must be taken into account. Some of these differences are unrelated to the model. For example, the Soviet Union had a larger military-industrial production sector and its constituent countries suffered greater disruption to their

41. These scores are assigned after evaluating a checklist of subcategories for each of political rights and civil liberties; for details, see Freedom House, "The Comparative Survey of Freedom 1995-96," pp. 2-3 (available on the Freedom House worldwide web page). Their civil liberties measure is highly correlated with their political freedom index, and we do not find any differences between our econometric results for the two variables. The results reported below use only "political freedom."

42. See Shor (1997).

43. For example, Åslund, Boone, and Johnson (1996) compare four sets of rankings of former Soviet countries by the World Bank, the International Monetary Fund, the EBRD, and Ernst \& Young and find much agreement. 
trade following the fall of communism. Other differences may reflect heterogeneity in the model's parameters. For example, countries in the former Soviet Union may have an inferior technology for the production of public goods. Their much longer communist history meant that they did not have the commercial laws and other capitalist institutions developed during the 1920s and 1930s that Poland, Hungary, and the Czech Republic could go back to after the fall of communism. Such heterogeneity would lead to a dispersion of outcomes similar to that predicted by our model with multiple equilibria.

An obvious way to control for these differences is to use a dummy variable for belonging to the former Soviet Union; we run each of our regressions both with and without this control. Both the heterogeneity model and the formal model detailed above predict that the FSU dummy is correlated with the share of the unofficial economy, and also that it reduces the partial correlation between that share and our measures of $t$ and $Q$.

Empirically, we cannot distinguish these two models. However, it is important to emphasize that it does not much matter whether the data are generated by unmeasured heterogeneity between eastern Europe and the former Soviet Union or by a model with multiple equilibria. Our model suggests that relatively small differences in initial conditions may be magnified by the mechanisms that we describe, leading to large differences in the size of the unofficial economy and in performance more generally. In our empirical work, we attempt to understand the relationship between taxation and regulation, the provision of public goods, the size of the unofficial economy, and growth. The basic message of our story about the role of the unofficial economy in transition holds regardless of whether the FSU has ended up where it is because of bad history, bad policies, or bad luck.

In addition to the FSU dummy, we include the original share of the unofficial economy as a control variable. The initial year of reform is taken to be the "year of most intense reform," as identified by Anders Åslund, Peter Boone, and Johnson, and is set equal to zero. ${ }^{44} \mathrm{We}$

44. See Åslund, Boone, and Johnson (1996, table 3). Determining the first year of reform is uncontroversial for most countries. All members of the former Soviet Union (with the arguable exceptions of Lithuania and Estonia in the Baltics) clearly started reform in 1992, while Poland, Hungary, and Romania began in 1990, and Albania in 1992. The Czech Republic, Slovakia, and Bulgaria could be interpreted as having begun 
determine the beginning of reform by substantial price liberalization, which, in effect, means that every country is assumed to have started reform by $1994 . .^{45}$

\section{Effects on the Unofficial Economy}

In this section, we examine the relationship between the tax and regulatory burden and the supply of public goods, on the one hand, and the size of the unofficial economy, on the other.

\section{The Share of the Unofficial Economy}

Table 1 shows the results of estimating the share of the unofficial economy $(U)$ in total GDP, using the electricity consumption-based methodology explained above. The table reveals some interesting facts. The average unofficial share in east European countries starts in 1989 at 16.6 percent, peaks at 21.3 percent in 1992 , and falls to 19.0 percent by 1995 . By contrast, the average unofficial share in former Soviet countries starts at 12.0 percent and rises to 36.2 percent in 1994 before dropping to 34.4 percent in 1995 . The upper panel of figure 2 shows the pattern of the average share of the unofficial economy in Europe, in the Baltics, and in the rest of the FSU over the period 1989-95; the lower panel of the figure compares the share of the unofficial economy in Poland and Russia over the same period. Between 1989 and 1995, the unofficial economy's share in both Poland and Romania fell by around 3 percentage points. In Russia and Ukraine, by contrast, the share of unofficial economy rose by 29.6 and 36.9 percentage points, respectively, over the same period. In both Belarus and Uzbekistan, the share of the unofficial economy is low; it has hardly increased in

in 1990 or 1991 . At least for the analysis in this paper, these differences as to when reform "started" do not seem to affect the results.

45. The main alternative way of dating reform is according to when the IMF deems countries to "have stabilized." This method is used by Fischer, Sahay, and Végh (1996b) and by Hellman (1996). Using this measure in our cross-country regressions does not appear to make a difference and these results are not reported. However, it does have implications for the interpretation of individual country reform effects: most notably, by this method, Russia "reformed" in April 1995, in contrast with our date of January 1992, under the Åslund, Boone and Johnson (1996) method. 


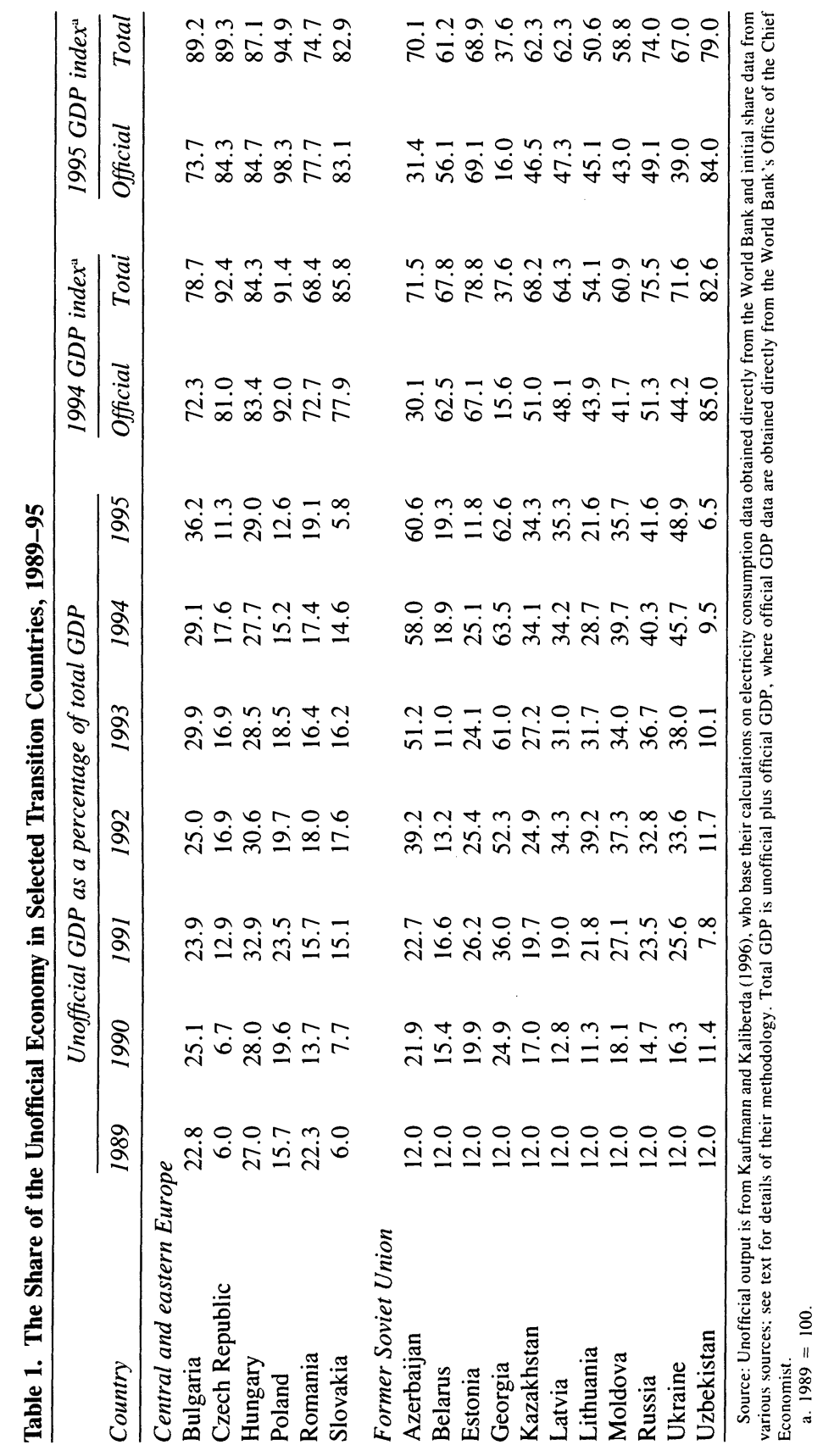


Figure 2. The Share of the Unofficial Economy in Transition Countries, 1989-95 Unofficial/total GDP (percent)
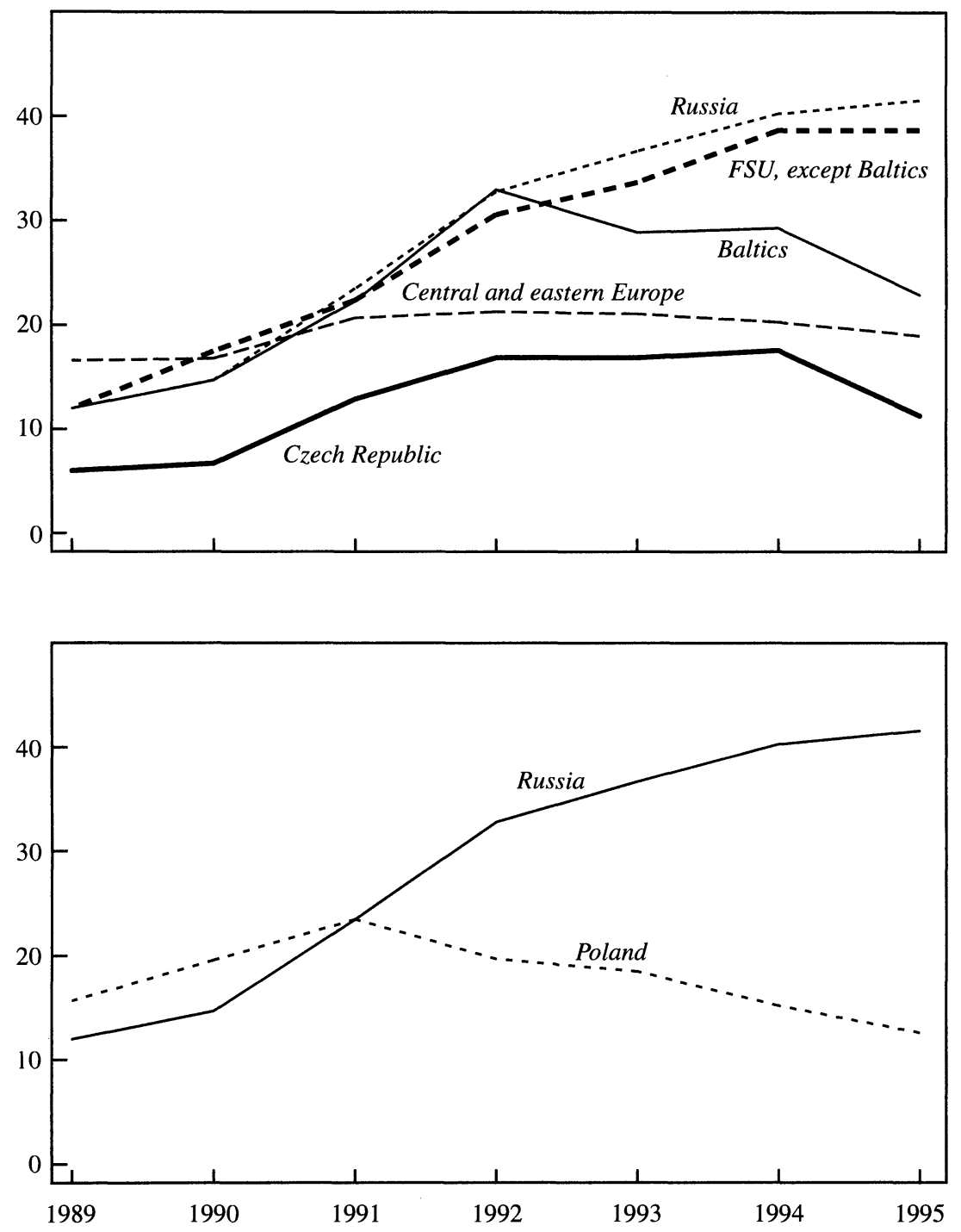

Source: See table 1

a. For countries in sample, see table 1 . 
Belarus and has actually declined in Uzbekistan. This is consistent with our notion that in these countries the state has suppressed the unofficial sector. ${ }^{46}$

Adjusting for the unofficial economy implies a substantial revision in GDP numbers for some countries, as is also shown in table 1. For example, we estimate that Russian GDP in 1995 was actually around 75 percent of its 1989 level, rather than the 49.1 percent indicated in official statistics. The countries with the greatest drop in official GDP from 1989 to 1995 receive the largest upward correction in our total GDP estimates. For example, Georgian GDP in 1995 is estimated to be 37.6 percent of its 1989 level, not the 16.0 percent suggested by official statistics, while for Poland our estimate of total GDP (1994 or 1995 relative to 1989) is actually slightly smaller than the official number. The direction of the correction should be kept in mind when interpreting the empirical results below.

\section{The Impact of Taxation, Regulation, and Corruption}

Figures 3 and 4 offer a first look at the data. Figure 3 shows the share of the unofficial economy in total GDP and the Central European Economic Review's tax fairness index. In general, a lower tax fairness score is associated with a higher share of the unofficial economy, just as the model predicts. In Belarus and Uzbekistan, however, the government has been able to sustain low tax fairness without a large part

46. These estimates of the unofficial economy are generally consistent with other estimates for particular countries, based on microsurveys and other independent estimations. For example, Kaufmann (1997), using firm-level surveys, finds that about half of value added is not reported in Ukraine. For Poland, Zienkowsky (1996) estimates the unofficial economy at less than 20 percent by 1993 .

We would emphasize, however, that our estimation procedure is subject to a margin of error. The pretransition estimates of the unofficial economy for eastern Europe could be on the high side. Further, the energy efficiency gains from energy price adjustments in those countries may, in reality, have exceeded our assumed "efficiency elasticity" assumptions. But these effects would counteract each other, resulting in similar posttransition estimates of the unofficial economy. One could only obtain significantly larger estimates than ours for the unofficial economies of eastern Europe by the mid-1990s if the initial baseline estimates were too low or the energy efficiency gains were substantially larger. For the FSU economies, it is plausible both that the initial estimate of 12 percent is somewhat low, and that there have been more gains in energy efficiency than we assume. Thus it may be that by the mid-1990s, the unofficial economy in the FSU was even larger than we estimate. 
Figure 3. Tax Fairness and Unofficial Output, Selected Transition Economies, 1995 Unofficial/total GDP (percent)

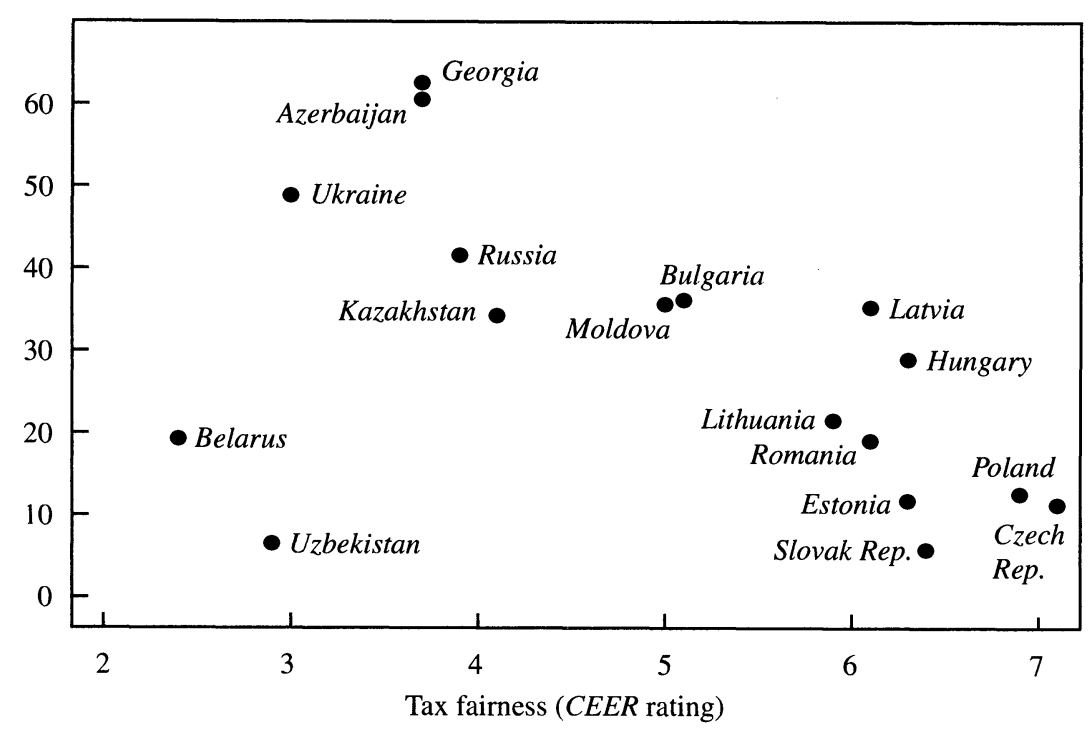

Source: Tax fairness ratings are from the Central European Economic Review (CEER); see appendix A. For data on the unofficial economy's share, see table 1.

of the economy moving into the unofficial sector. Similarly, figure 4 shows that the quality of public goods (measured in this case by the CEER index of legal safeguards for investment) is higher where the share of the unofficial sector is lower. Again, Belarus and Uzbekistan are outliers: the quality of public goods is poor, but relatively little of their economies has switched into the unofficial sector.

Figures 3 and 4 suggest that our basic model does not adequately describe Belarus and Uzbekistan. The most likely reason is that the assumption of free mobility of economic activity between the official and the unofficial sectors is violated: the state has remained so repressive that entrepreneurs cannot switch into the unofficial sector. Figure 5 confirms this interpretation with data on the Freedom House indexes of rule of law and political process. Belarus and Uzbekistan-along with Tajikistan and Turkmenistan, which are not in our sample due to lack of electricity data-are by far the most politically repressed countries. To encompass them, we need to expand the model to allow for a 
Figure 4. Legal Safeguards and Unofficial Output, Selected Transition Economies, 1995

Unofficial/total GDP (percent)

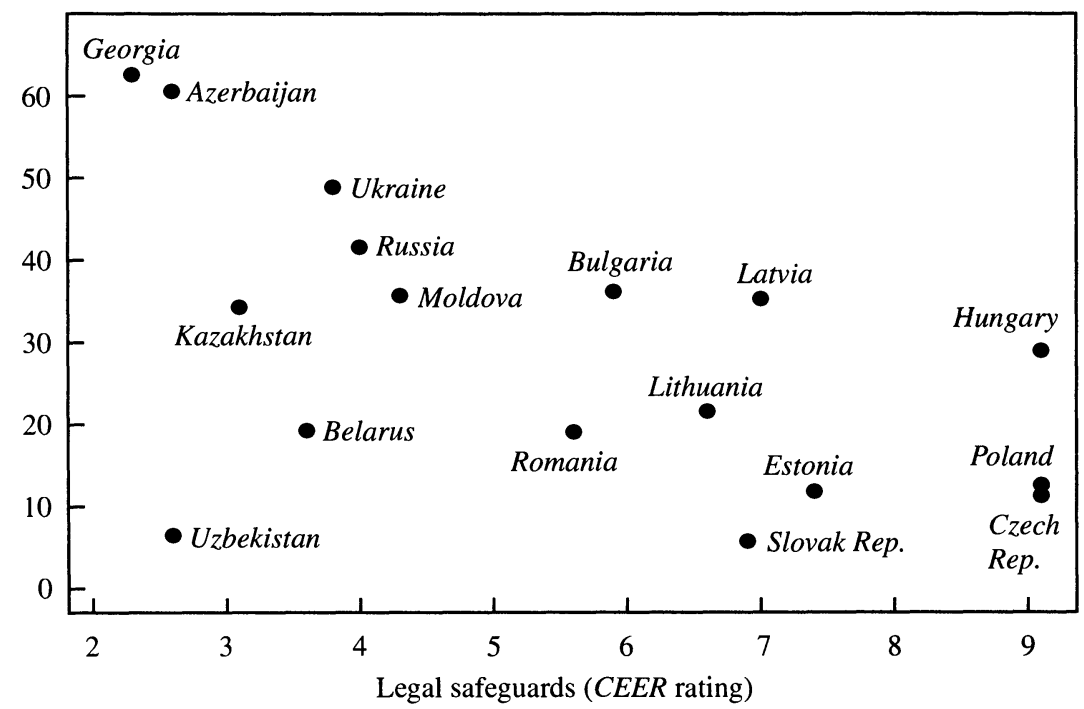

Source: Legal safeguards ratings are from the CEER; see appendix A. For data on the unofficial economy's share, see table 1

state that represses the unofficial sector rather than competing with it. Below, we continue to include Belarus and Uzbekistan in the graphs, but omit them as observations in our regressions.

Table 2 reports the results from regressions of the share of unofficial economy in total GDP on measures of state control over the economy (that is, our $t$ variables) for a cross-section of fifteen countries. A negative coefficient implies that a lower $t$ is associated with a larger share of the unofficial economy in total GDP. For each variable, we report in the first column the results for ordinary least squares regressions, with only the state control variable and a constant. In the second column, we include a dummy for belonging to the former Soviet Union; and in the third column, we control for countries' initial (prereform) shares of unofficial activity.

The first independent variable measuring state control is the World Bank measure of internal liberalization, which lies between 0 and 1 . This variable is significantly correlated with the unofficial share of the 
Figure 5. Political Process and Rule of Law, Selected Transition Economies, 1995

Rule of law (Freedom House rating)

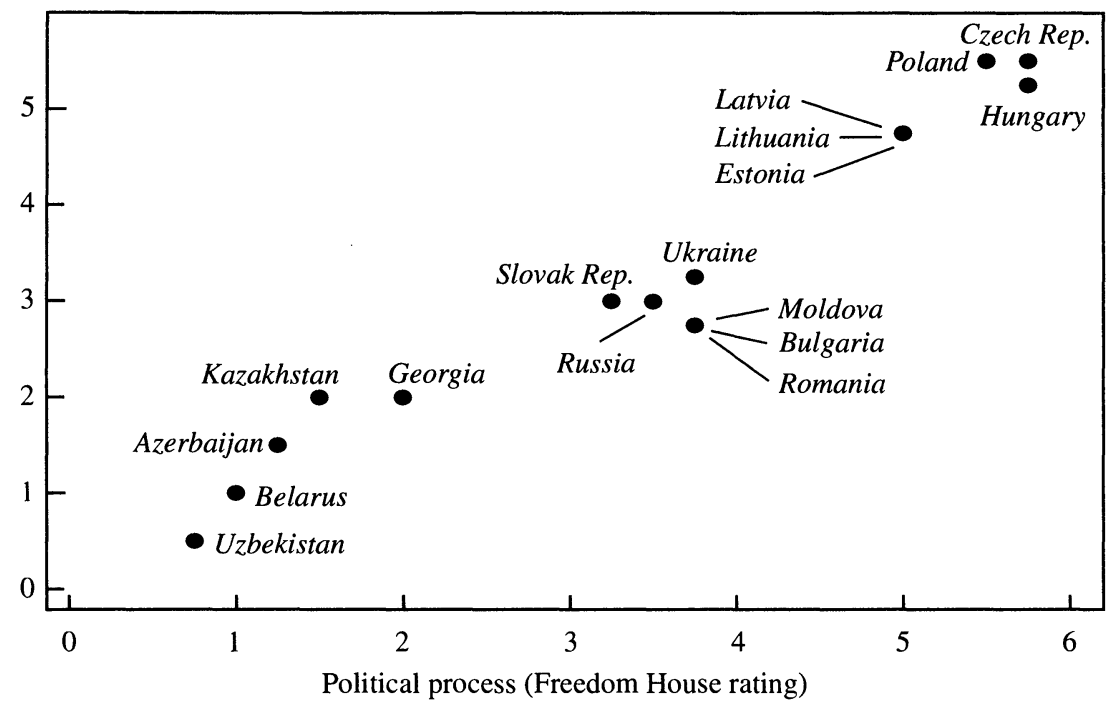

Source: Ratings are from Freedom House; see appendix A.

economy, regardless of whether one uses the dummy for belonging to the FSU. An increase of 0.1 in this index in 1995 reduces the share of the unofficial economy by around 13 to 16 percentage points.

The second independent variable, the EBRD's measure of external liberalization, runs from 1 to 5 , although the countries actually lie between 2 and 5 . This variable is significant both by itself and when we include the FSU dummy and initial share. A 1 point increase in this index reduces the share of the unofficial economy by 14 to 18 percentage points.

The third independent variable is the EBRD's measure of large-scale privatization, on a scale of 1 to 5 . This policy variable is negatively correlated with the unofficial share of total GDP, and the coefficient suggests that a 1 point increase in the score of large-scale privatization is associated with a 10 to 13 percentage point reduction in the share of the unofficial economy. When we use the former Soviet Union dummy instead of the initial unofficial share, this result is weaker but still 


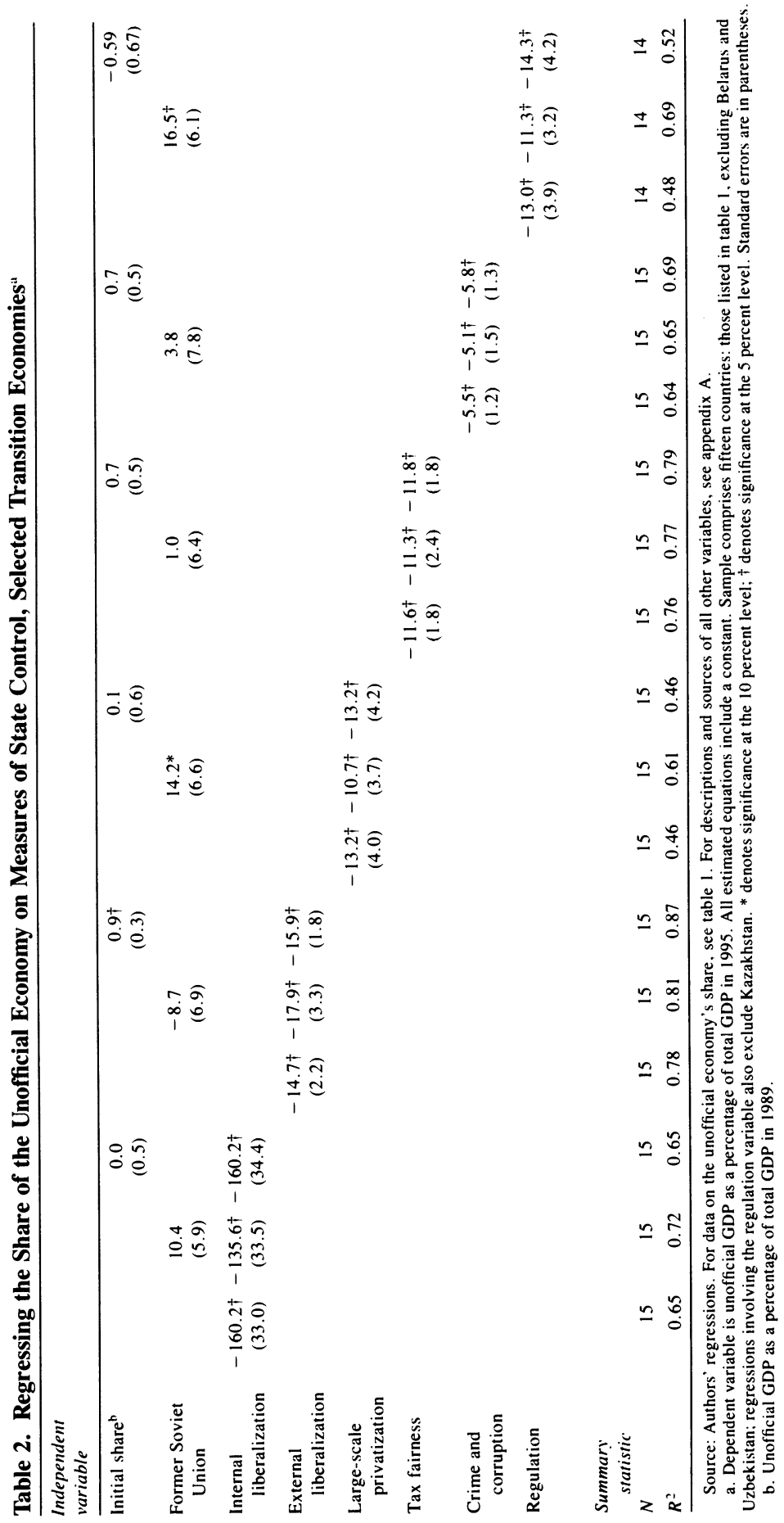


significant. The FSU dummy itself is significant only at the 10 percent level.

The fourth independent variable, the CEER tax fairness index, is also significant and has the predicted sign in the regression. As figure 3 shows (Belarus and Uzbekistan aside), fairer taxes mean that a smaller share of the economy is unofficial. ${ }^{47}$ This evidence supports the proposition that higher tax burdens drive firms into the unofficial economy.

The fifth and sixth independent variables represent two types of "taxation" that do not yield government revenues: corruption and regulation. Our proxy for corruption is the CEER index of crime and corruption, which ranges from 1 to 10 . This measure is significant with the expected sign when used in the share regression. A 1 point improvement in the index - that is, a decrease in corruption-reduces the share of the unofficial economy by 5 to 6 percentage points.

Our proxy for regulation is the Heritage Foundation's regulation index. A 1 point increase in this index lowers the unofficial economy share by 11 to 14 percentage points. Figure 6 confirms the negative relationship between regulation and the share of the unofficial economy.

\section{The Impact of the Legal Environment}

We use four measures of the legal environment. These can be thought of as proxying for $Q$ in our model; that is, the supply of public goods to the official sector. The first two measures are evaluations by two different CEER panels of "legal safeguards for investment" and of the "rule of law." The third and fourth measures, from the EBRD, evaluate the countries in terms of the de jure extensiveness and the de facto effectiveness of legal systems in protecting investment.

While figure 4 presents the relationship between the CEER measure of legal safeguards and the share of the unofficial economy, figure 7

47. The $C E E R$ and Heritage Foundation estimates of tax fairness differ significantly. The Heritage Foundation's taxation index (where a higher score means a greater effective tax rate) is not significantly correlated with the unofficial share of the economy. In the Heritage Foundation measure, tax fairness is relatively low (a score of 1 out of a potential 4 ) in economies with a relatively low unofficial economy share (such as the Czech Republic and Hungary) and in those with a relatively high share (such as Russia and Azerbaijan). Since the Heritage Foundation does not provide data on Uzbekistan, we have only fourteen data points when we use its measures of reform. 
Figure 6. Regulation and Unofficial Output, Selected Transition Economies, 1995

Unofficial/total GDP (percent)

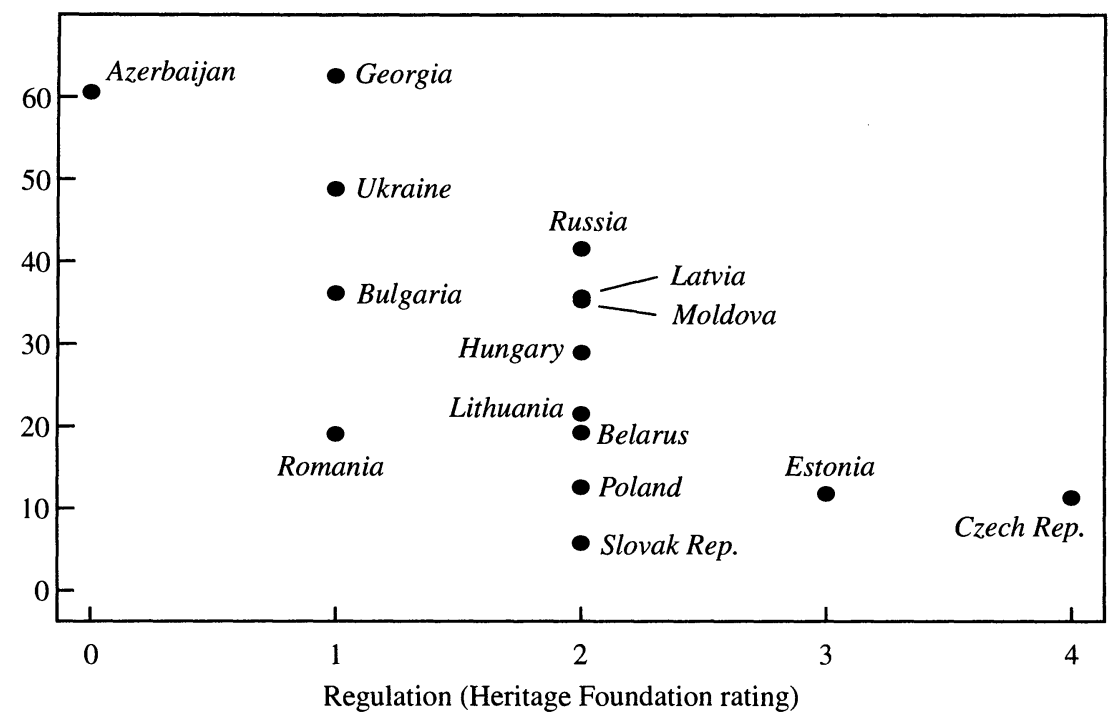

Source: Regulation ratings are from the Heritage Foundation; see appendix A. For data on the unofficial economy's share, see table 1 .

shows the relationship between the EBRD measure of legal effectiveness and that share. Together, these figures yield two conclusions. First, across most countries, there is a negative relationship between the supply of law and order to the official economy and the relative size of the unofficial economy. Second, Belarus and Uzbekistan are again exceptions, with low provision of public goods and yet low shares of the unofficial economy. As above, we omit these two countries from the regressions.

Once again, there are sharp differences between eastern Europe and the Baltics on one hand, and the rest of the FSU, on the other. Eastern Europe and the Baltics have significantly higher scores on legal environment. In the CEER measure of the rule of law, only Bulgaria of the east European countries has a lower score than the highest-scoring FSU country outside of the Baltics, Moldova, and the difference is very small. The difference in the CEER measure of legal safeguards is even 
Figure 7. Legal Effectiveness and Unofficial Output, Selected Transition Economies, 1995

Unofficial/total GDP (percent)

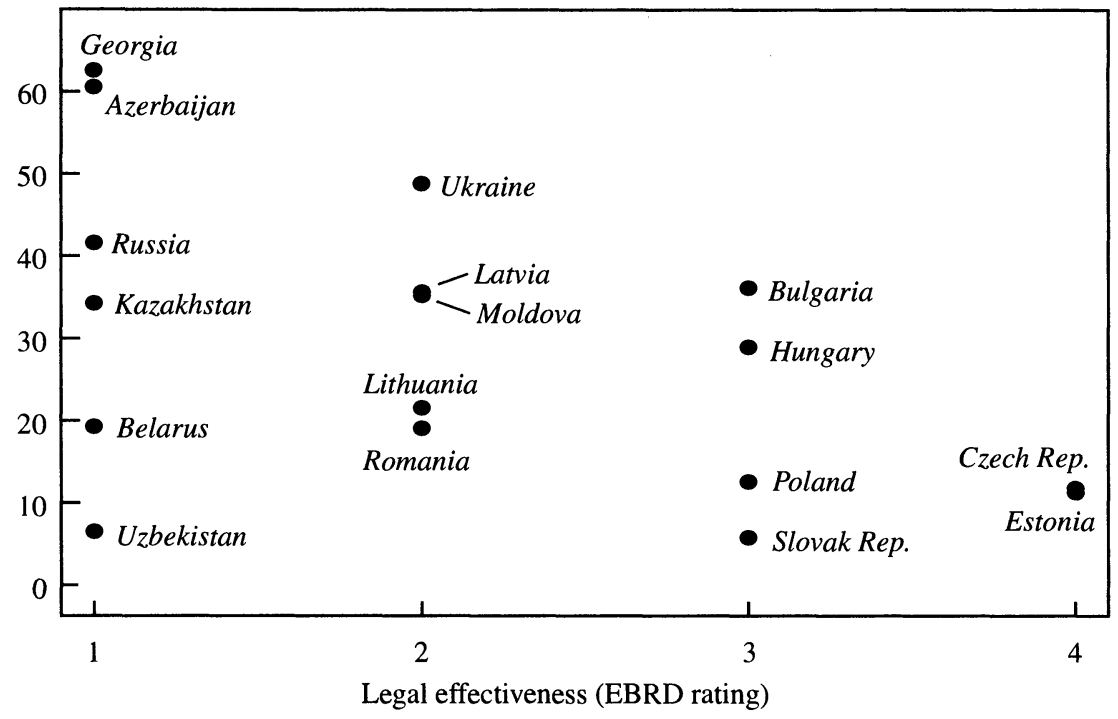

Source: Legal effectiveness ratings are from the European Bank for Reconstruction and Development; see appendix A. For data on the unofficial economy's share, see table 1.

more striking (see figure 4): the lowest score among the east European and Baltic countries is 5.6 (Romania) and the highest score within the FSU, excluding the Baltics, is 4.3 (Moldova).

Table 3 shows the relationship between the four measures of the legal environment and the share of the unofficial economy in 1995. A higher score means a better environment for official business. In table 3 , all the measures have the predicted sign and are significant in explaining the unofficial economy share. This is strong support for the theoretical prediction that the unofficial economy is larger where public goods are poorer in the official sector and, in particular, where the rule of law is weaker. Controlling for initial share, a 1 point increase in the index of legal safeguards (which ranges from 1 to 10 ) is associated with a 6.3 percentage point fall in the share of the unofficial economy; a change in the rule of law index has a slightly smaller effect. The indexes 


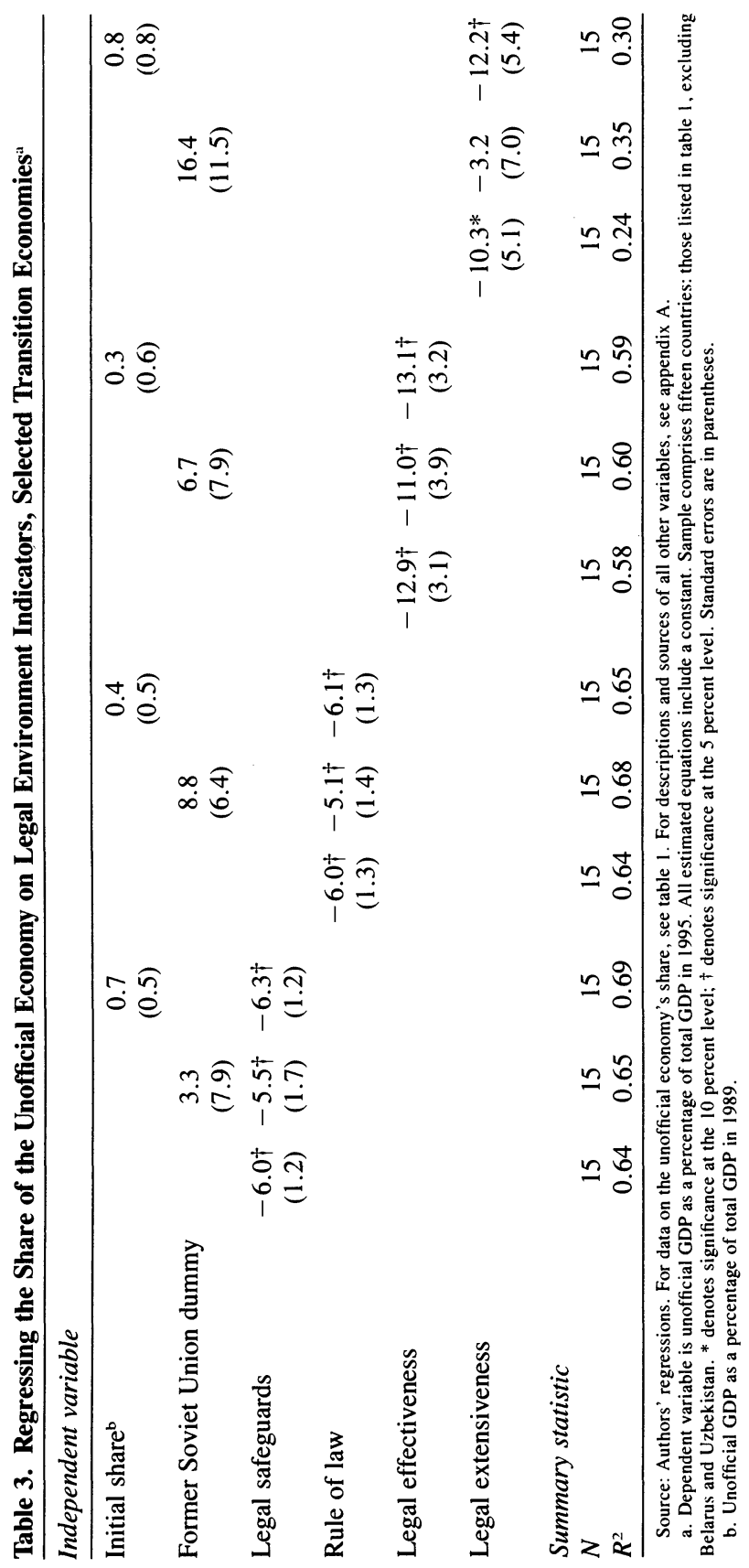


of legal effectiveness and extensiveness have a similar size effect, although it is hard to compare precisely because they range from 1 to 5. The first three measures of legal environment retain their significance if we use the FSU dummy, but the effect is weaker-consistent with the possible multiplicity of equilibria. All four measures are significant when one controls for the initial share of the unofficial economy.

The Relationship between Taxation, Government Spending, and the Quality of Public Goods

Our model is based on public finance mechanisms that relate tax revenue $(T)$ and the provision of public goods $(Q)$. As such, it makes other predictions in addition to those tested in tables 2 and 3. First, tax revenues should be lower when the tax burden is excessive, as measured by a low tax fairness score. Second, assuming that tax revenues and government spending are strongly positively correlated, lower tax revenues should be associated with a lower supply of public goods. In this subsection, we briefly examine the evidence bearing on these predictions.

Figure 8 confirms that with the exception of Belarus and Uzbekistan, tax revenue (as a percentage of total GDP, which includes the unofficial economy) improves with tax fairness. Equivalent 1994 data indicate that both tax revenue and tax fairness are high in the Czech Republic and Poland. From figure 8, Russia has an intermediate tax fairness score, but not high enough for a lot of tax revenue. Belarus and Uzbekistan are anomalous because the high level of political repression enables the state to keep firms in the official sector (and therefore to maintain its revenue), even though tax fairness and the level of public goods provision are both low.

Our model assumes that tax revenue and government spending are equivalent. Figure 9 shows the time series of tax revenues as a share of total GDP for Russia and Poland during transition. In Poland revenue initially fell with reform, but then increased; in Russia, it continued to fall. More generally, appendix D presents the available numbers for 1994 and 1995 on general government spending as a percentage of both official and total GDP. General government spending in Poland was 48.8 percent of official GDP in $1989,39.8$ percent in 1990 , and 47.5 percent in 1994; in the Czech Republic it was 60.1 percent in 1990 and 
Figure 8. Tax Fairness and Tax Revenue, Selected Transition Economies, 1995

Tax revenue/total GDP (percent)

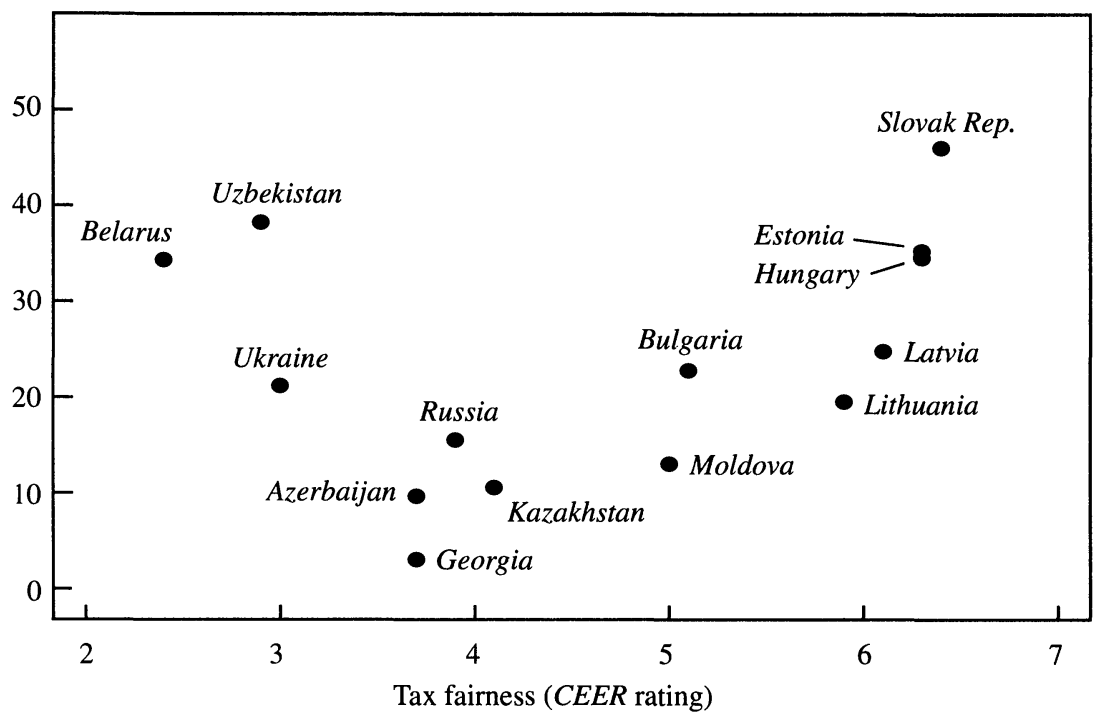

Source: Tax fairness ratings are from the CEER; see appendix A. Tax revenue data are from European Bank for Reconstruction and Development (1996). For GDP data, see table 1.

50.0 percent in 1994; and in Hungary it was 53.5 percent in 1990 and 56.1 percent in 1995. By contrast, Russian government spending fell from 60.5 percent of official GDP in 1992 to 31.9 percent in 1995. As a share of total GDP, general government spending was around 40 percent for Poland in 1994 and below 20 percent for Russia in 1995. There has been a large decline in general government spending as a percentage of GDP in the FSU countries other than the Baltics, but not in eastern Europe or the Baltics.

Figure 10 shows that tax revenues are highly correlated with government spending. This figure suggests that internal and external borrowing generally are not critical determinants of the government budget in these countries and justifies our assumption that tax revenue approximately equals spending.

Figure $i 1$ completes the picture by showing a positive relationship between tax revenue and the quality of legal safeguards. It supports the importance of the public finance mechanism suggested by our model; 
Figure 9. Tax Revenue since Start of Reform, Poland and Russia

Tax revenue/total GDP (percent)

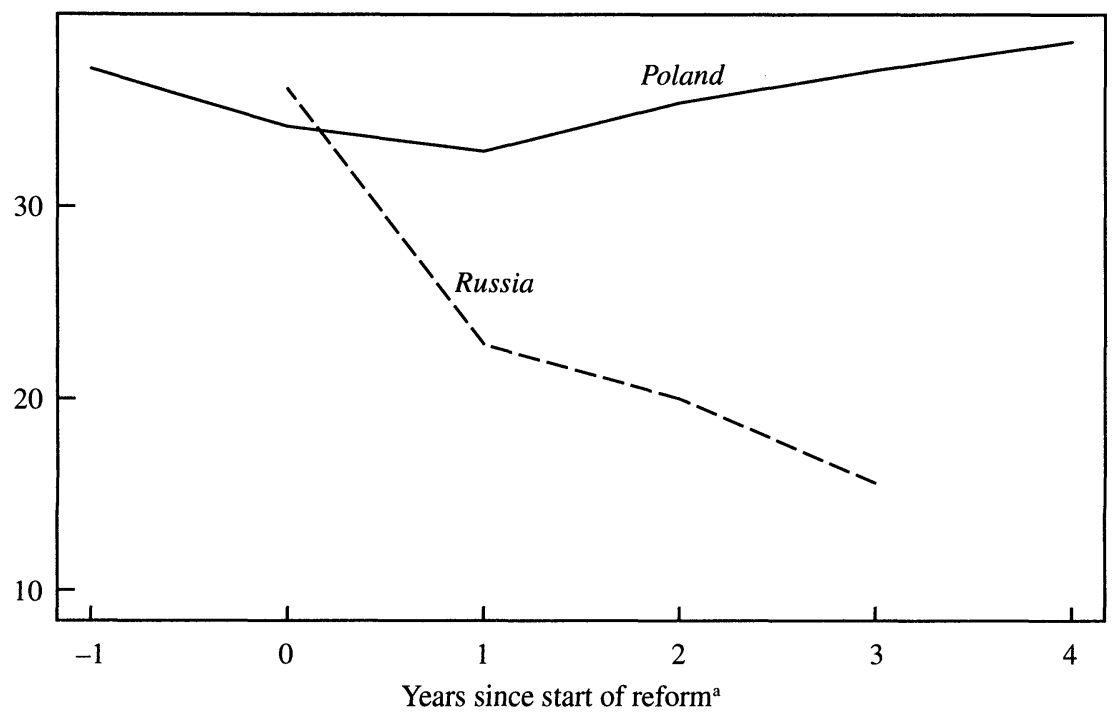

Source: First reform year is the year of most intense reform from Åslund, Boone, and Johnson (1996). Tax revenue data are from European Bank for Reconstruction and Development (1996). For GDP data, see table 1.

a. Year 0 is the first year of reform: for Poland $1990=0$, for Russia $1992=0$.

namely, that countries with fair tax systems raise more revenue and hence supply more public goods. In turn, the better supply of public goods may enhance the tax base and tax revenues.

\section{Summary}

The results of regressions using the share of the unofficial economy $(U)$ on the left-hand side confirm our theoretical predictions for both the tax rate $(t)$ and public goods $(Q)$ in the state sector. Liberalization, privatization, fairer taxation, and fewer regulations are all associated with a smaller unofficial economy. Better provision of public goods to the official economy is associated with a relatively larger official economy. Finally, public finance mechanisms do appear to be at work: countries with less distortionary tax and regulatory systems collect more tax revenue and provide more public goods to their official economies.

An ex ante plausible criticism of the model is that our electricity- 
Figure 10. Tax Revenue and Government Spending, Selected Transition Economies, 1995

Tax revenue/total GDP (percent)

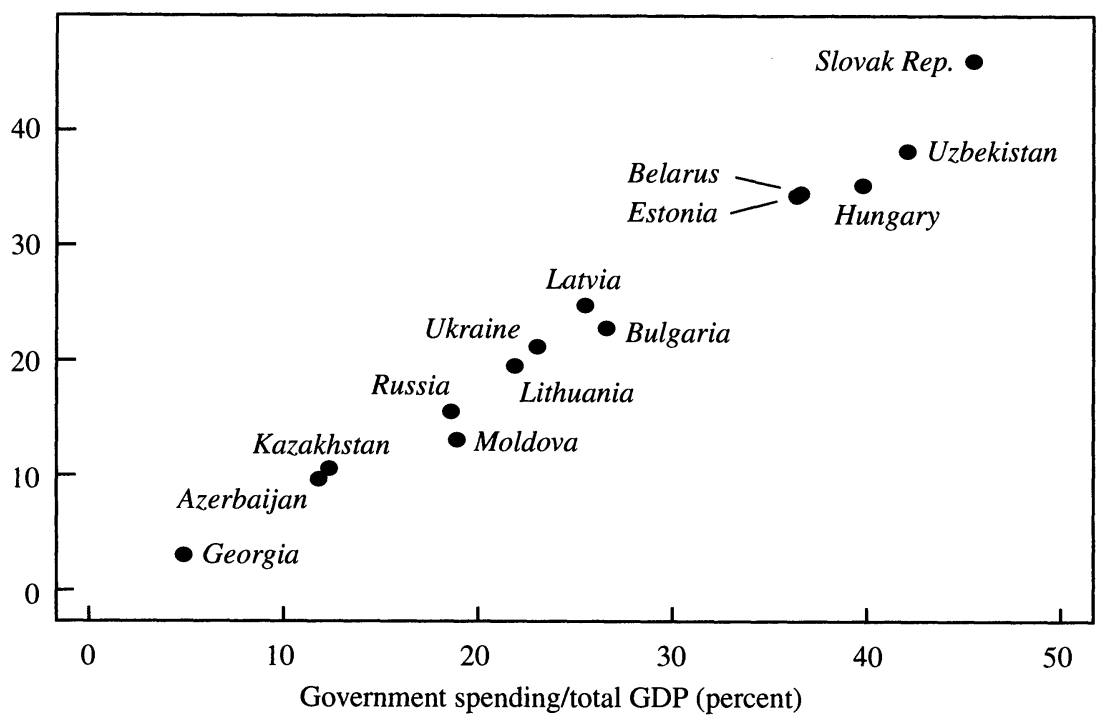

Source: Data for tax revenue and government spending are from European Bank for Reconstruction and Development (1996) For GDP data, see table 1.

based calculations of the unofficial economy are founded on too many implausible assumptions and are therefore too noisy to be useful. But if our estimates of the size of the unofficial economy are pure noise, why do they line up so well with the measures of $t$ and $Q$ ? The objection loses much of its power in light of the extremely strong raw correlations between our constructed measures of the unofficial economy and a variety of other variables. At this cross-sectional level, then, the predictions of the theoretical model are strongly confirmed.

\section{Effects on Growth}

In this section, we examine whether taxation and the supply of public goods are correlated with output growth across countries. Our model predicts that the effects of $t$ and $Q$ should be stronger on officially 
Figure 11. Legal Safeguards and Tax Revenue, Selected Transition Economies, 1995

Tax revenue/total GDP (percent)

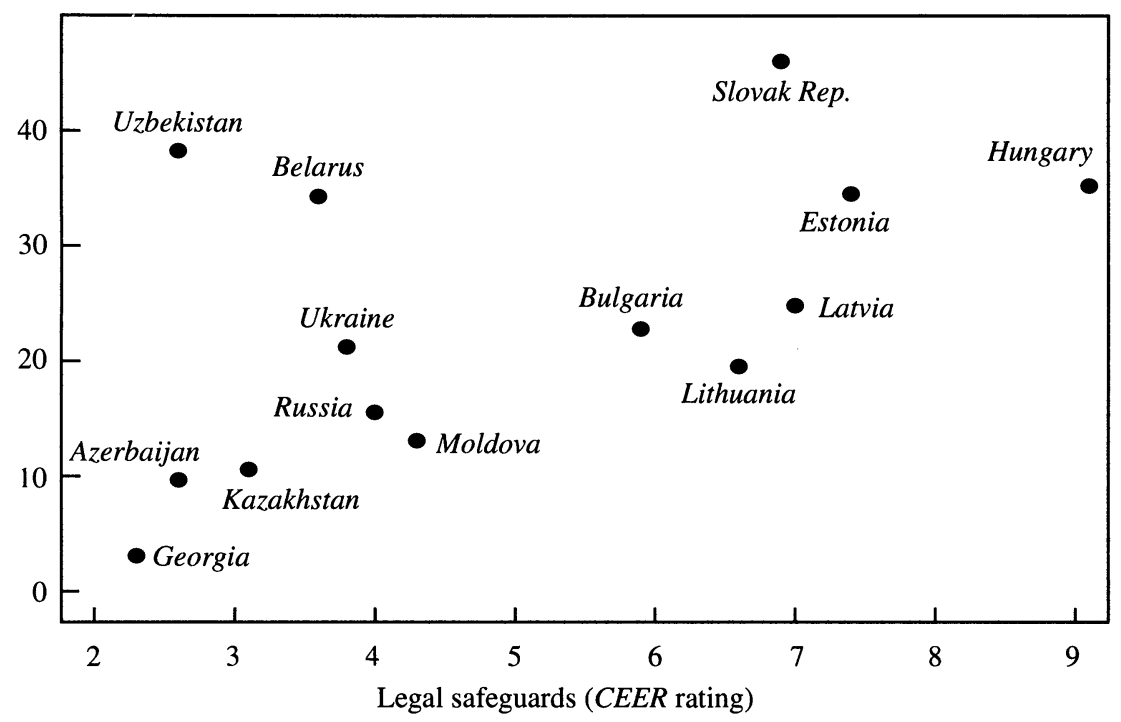

Source: Legal safeguards ratings are from the CEER; see appendix A. Tax revenue data are from European Bank for Reconstruction and Development (1996). For GDP data, see table 1.

measured GDP, because $t$ and $Q$ directly affect firms in the official sector. But there should also be an effect on total GDP (which includes the unofficial economy) if the unofficial sector is less efficient than the official sector.

For each country, we examine two measures of GDP (both indexes constructed to equal 100 in 1989): official output in 1995 and total output in 1995. The level of GDP in 1995 should capture cumulative performance better than the growth rate in any one year.

As above, we control for initial conditions. There is a strong relationship between the initial output decline (a negative number) in the "first" year of reform (as defined above) and total level of output in 1995: that is, when the initial output fall is larger, total output in 1995 is lower. The baseline regressions that we report in the tables below use the initial output fall as a control variable. We also check the results with a dummy for having belonged to the Soviet Union. 
Figure 12. Tax Fairness and Official Output, Selected Transition Economies, 1995

Official GDP (index, $1989=100)$

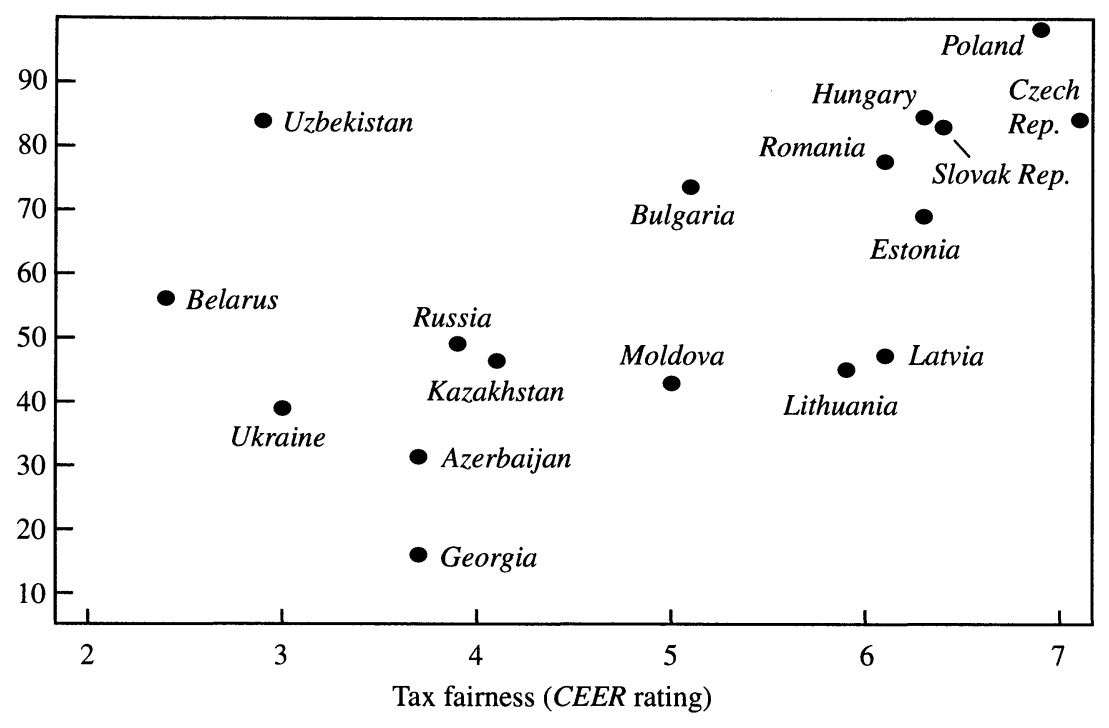

Source: Tax fairness ratings are from the CEER; see appendix A. For GDP data, see table 1.

\section{Official Output}

Figure 12 shows that, with the familiar exception of Belarus and Uzbekistan, higher tax fairness is associated with higher official output. Table 4 confirms a significant positive correlation between official output in 1995 and the EBRD's measures of external liberalization and privatization, as well as the $C E E R$ 's tax fairness index. A 1 point increase in external liberalization or privatization translates into about a 10 index point increase in the size of the official economy (controlling for belonging to the FSU). The tax fairness index also has a positive and significant coefficient, meaning that less distortionary taxes are associated with a smaller output decline.

These measures of the taxation parameter $(t)$ have a significant impact on 1995 output, even when we control for the initial fall in output. The index of crime and corruption is also significant. The Heritage Foundation measure of regulation has the predicted positive sign, 


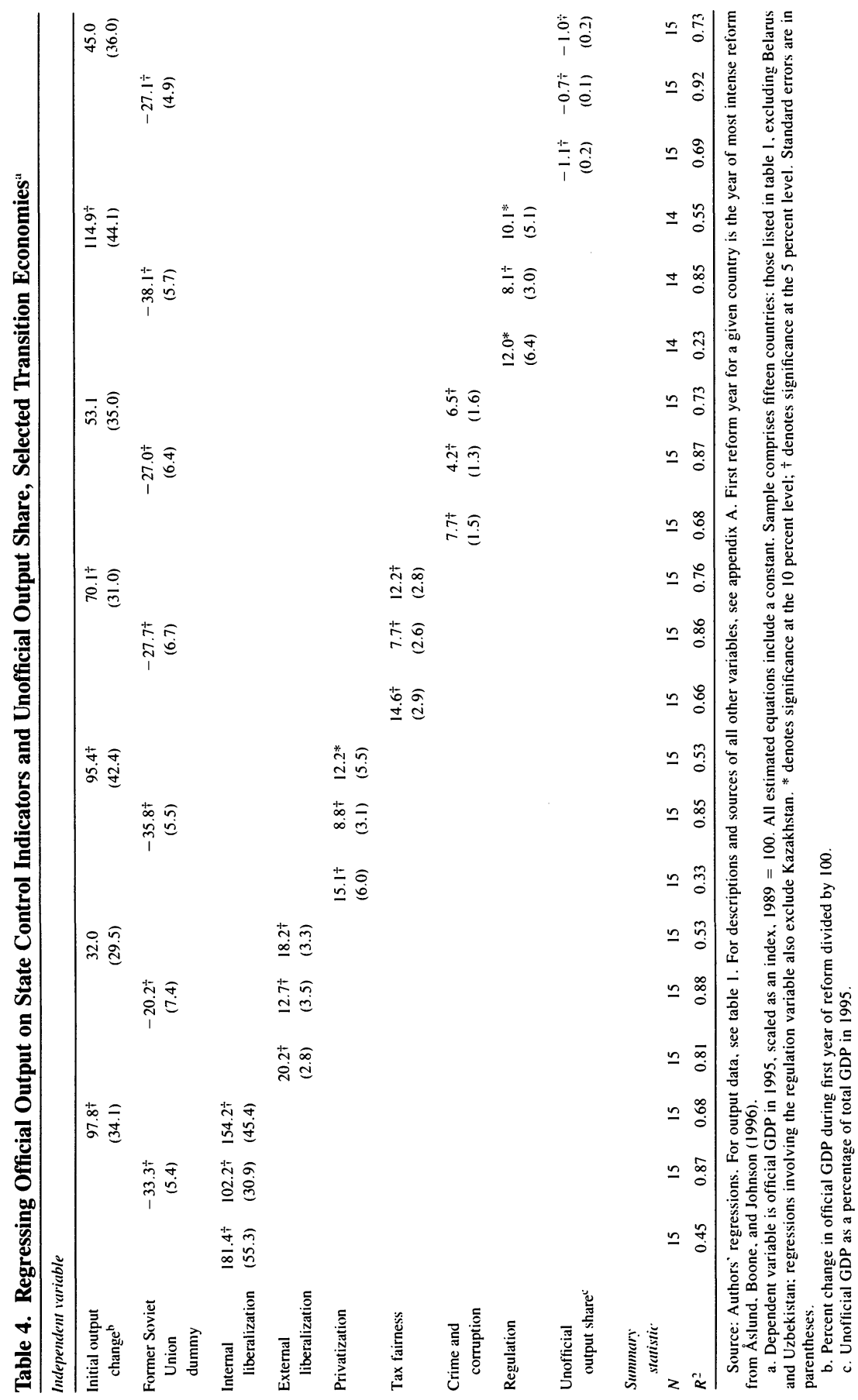


although in two specifications it is significant at only the 10 percent level. Finally, a higher share of the unofficial economy (as derived from our electricity calculations) is associated with a lower level of officially measured GDP. Without any controls, the $R^{2}$ in this regression is 0.69 . This result may be spurious, however, since the denominator in the share of the unofficial economy is the total size of the economy.

Table 5 shows that there are positive associations between official output performance and our four measures of legal reform. These results are robust to controlling for the initial fall in output. Without including any other variables, the $R^{2}$ in these regressions is as high as 0.72 (for legal safeguards), and it lies between 0.64 and 0.77 with the control for the initial fall in output.

The results in tables 4 and 5 become weaker when one includes a dummy for the FSU, or the FSU without the Baltics. The countries form two clusters: eastern Europe and the Baltics have relatively high public goods provision-in terms of a good legal environment-and better official output performance, on average, than the countries of the FSU other than the Baltics.

\section{Total Output}

Our measures of $t$ and $Q$ are less strongly correlated with total output than with official output. Table 6 shows that the standard measures of the broadly defined tax burden are not robustly significant. The external liberalization, tax fairness, and crime and corruption variables yield the strongest results, but none are significant when one includes a dummy for belonging to the former Soviet Union. Table 7 shows that all four measures of legal environment have a strong positive correlation with total output, but even this breaks down when one controls for belonging to the FSU. Figure 13 plots total GDP against tax fairness. Comparison with figure 12 , which also has tax fairness on the $x$-axis, illustrates the point that total activity is not as strongly correlated with institutional reform as is official activity.

These results provide some support for the argument that total output, and not just the official output, is reduced by excessive government intervention. At the same time, the results also suggest that the mafia provides firms that operate unofficially with public goods which, if not of so high a quality as those delivered by the state in the official sector, 


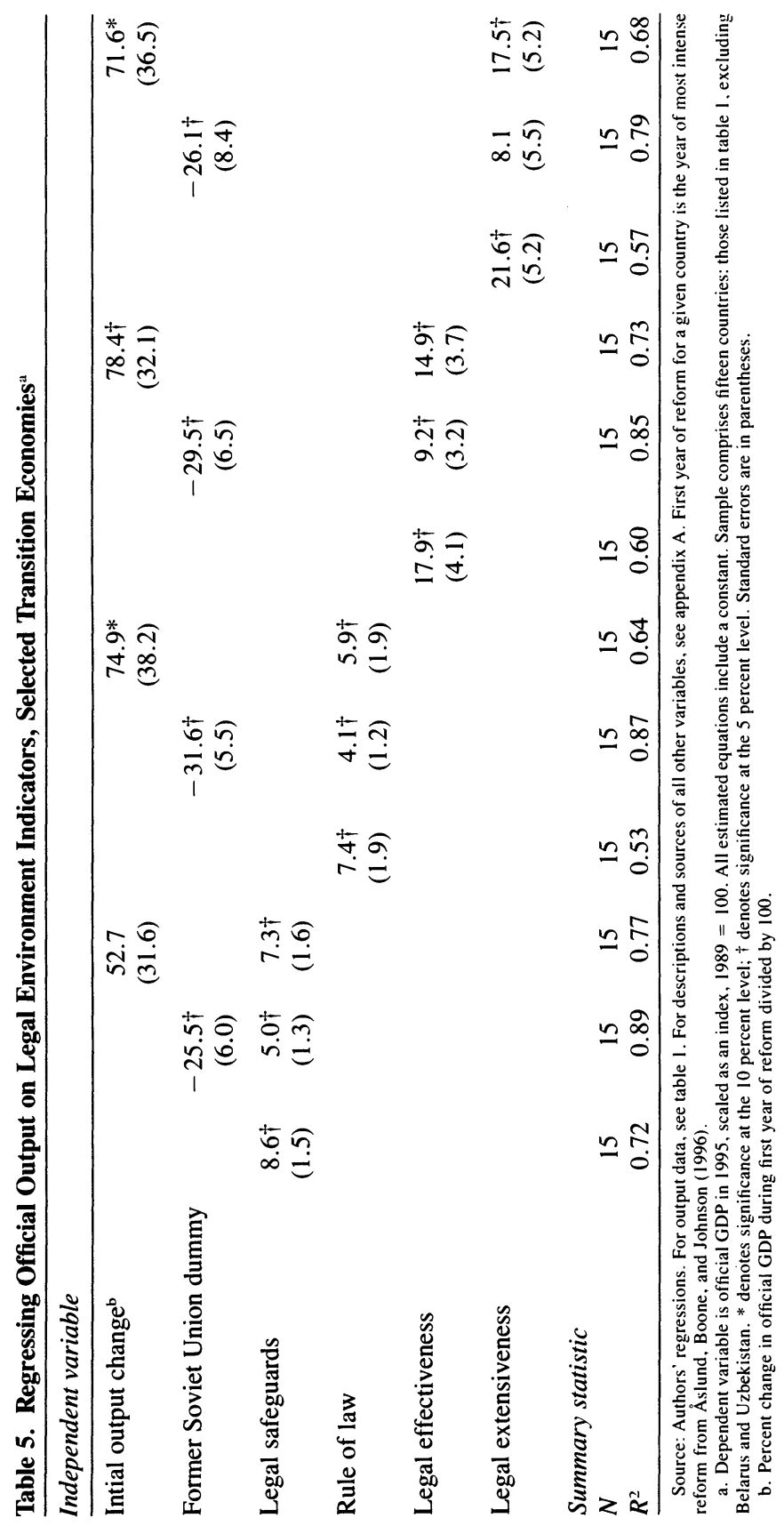




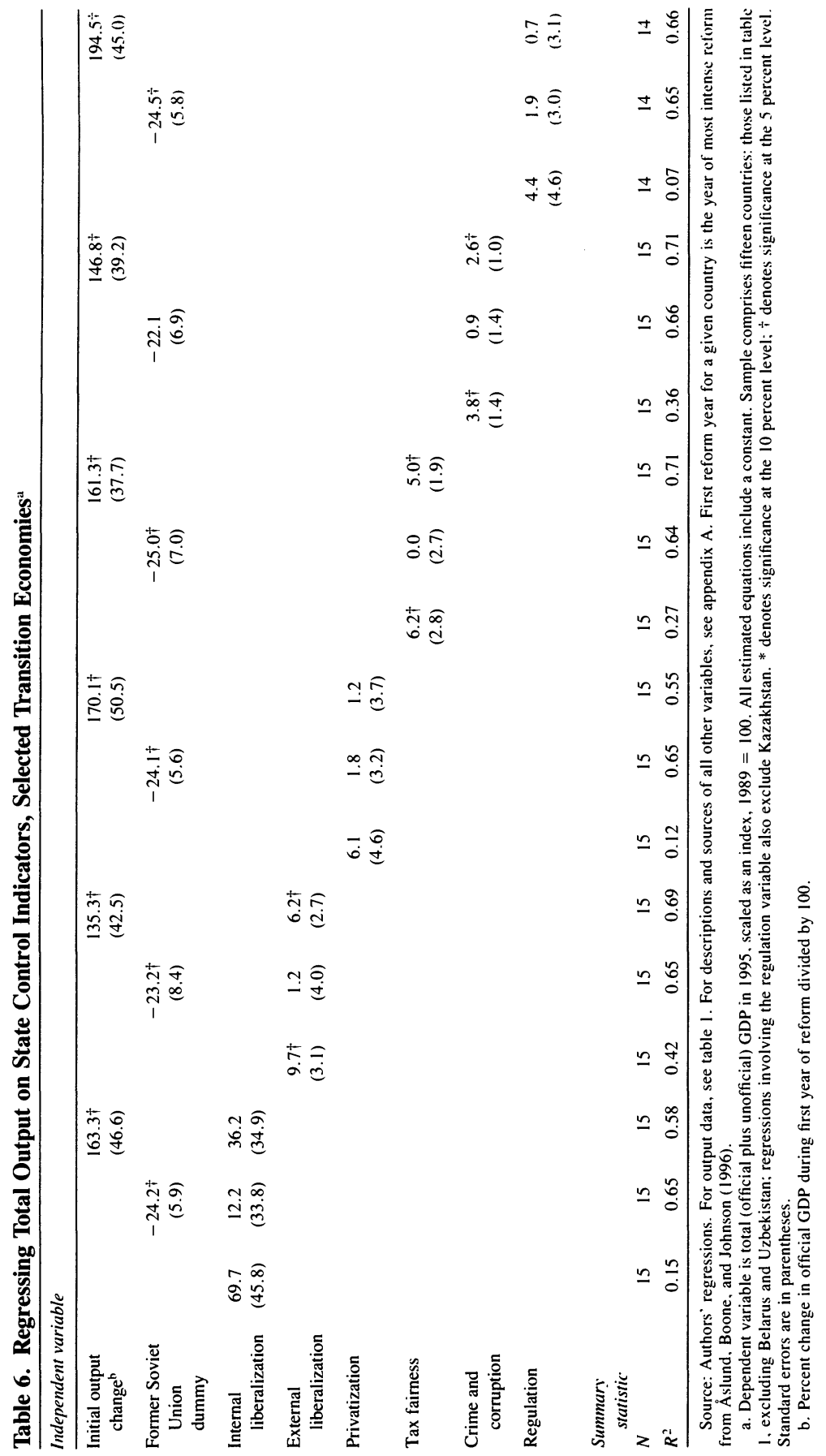




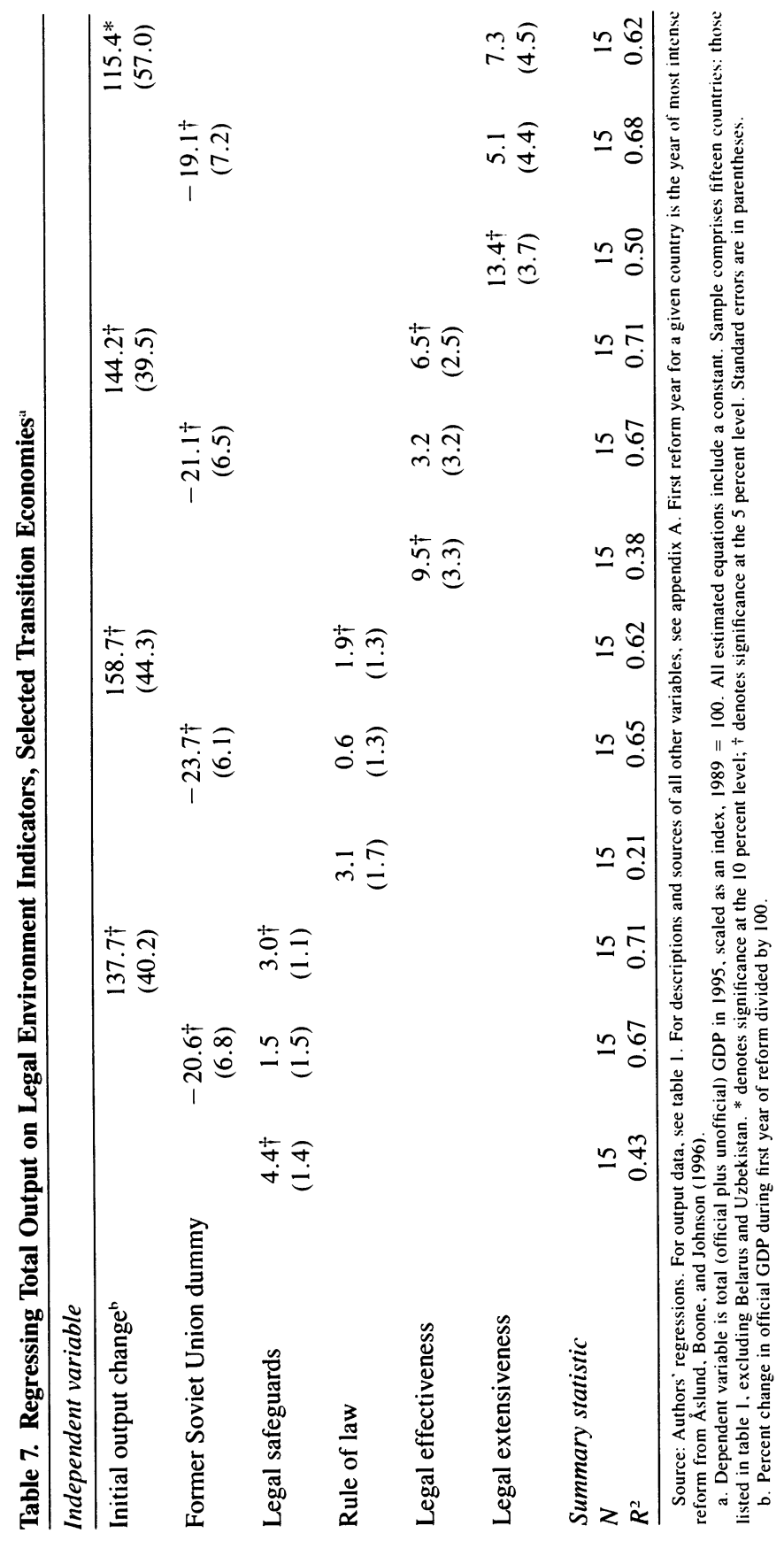


Figure 13. Tax Fairness and Total Output, Selected Transition Economies, 1995

Total GDP (index, $1989=100)$

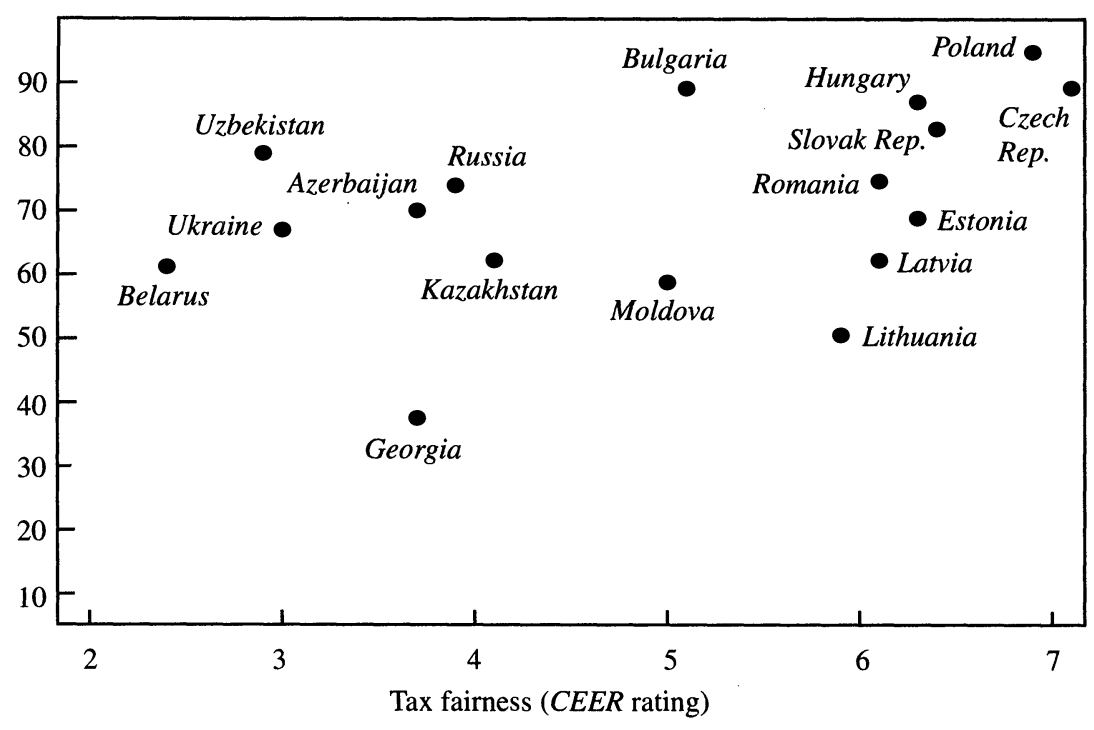

Source: Tax fairness ratings are from the CEER; see appendix A. For GDP data, see table 1.

are certainly good enough for the unofficial economy to function. Thus in transition economies, the mafia should not be viewed entirely as a social pathology. Rather, it is a market accommodation to the failure of the state to deliver an attractive combination of taxes and public goods. The mafia imposes taxes like the state and provides public goods like the state, though it evidently does not do so quite as efficiently as a well-functioning state.

\section{Stabilization Revisited}

Several recent studies have pointed to the benefits of stabilization for economic growth in transition economies. ${ }^{48}$ Table 8 confirms their findings with our sample. Countries with lower inflation and better fiscal balance have higher official output and a smaller unofficial sector share

48. See, for example, Åslund, Boone, and Johnson (1996); World Bank (1996b). 


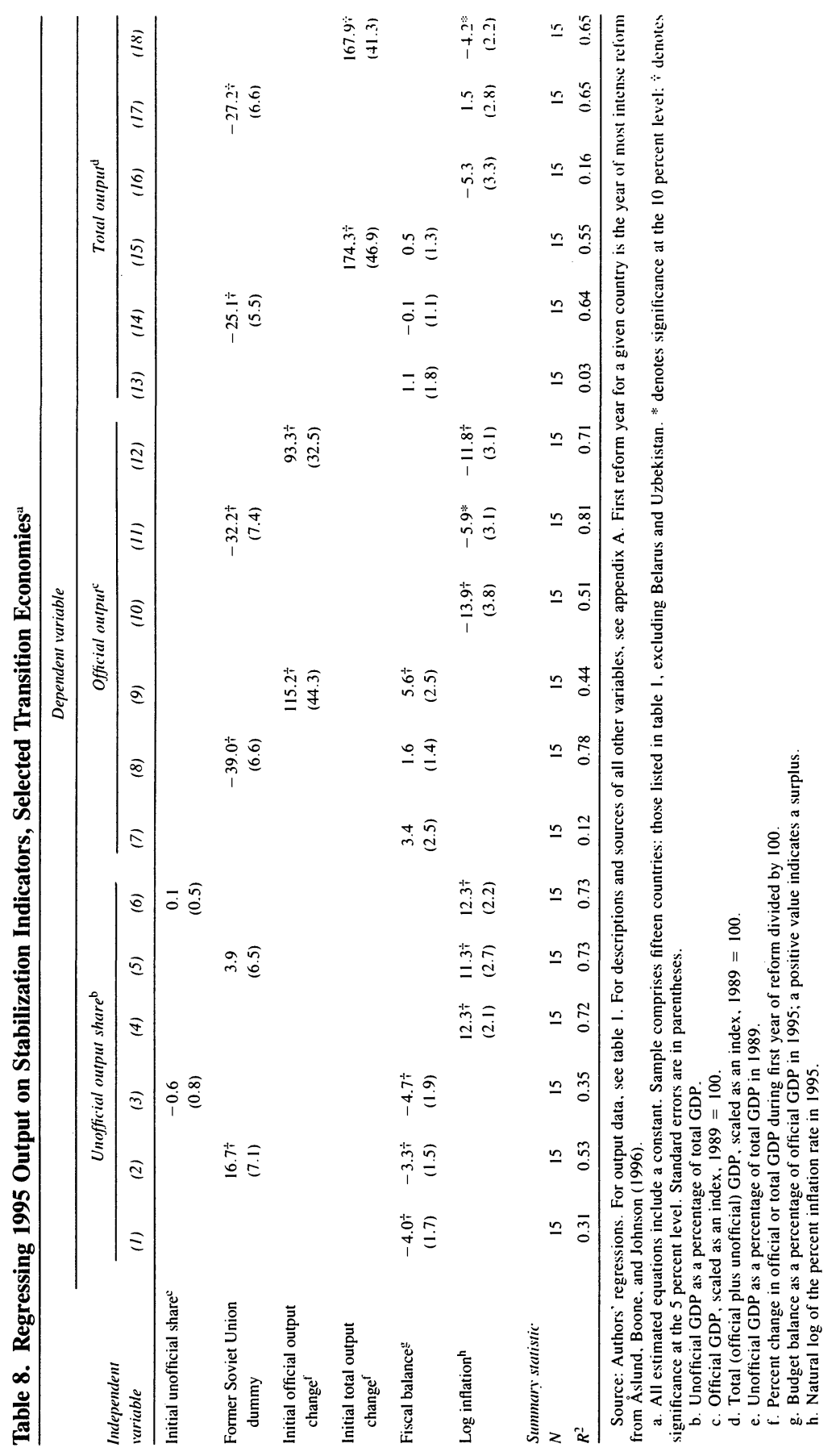


of the economy, although there is no robust result for total (official plus unofficial) output. The effect on official output is less strong than for our $t$ and $Q$ variables, in the sense that the coefficient on fiscal balance is insignificant and, when the FSU control is added, the coefficient on $\log$ inflation is significant at only the 10 percent level.

Åslund, Boone, and Johnson show also that all transition economies have eventually stabilized, although some have had more significant liberalization than others. ${ }^{49}$ Countries that deregulated their economies-that is, most of eastern Europe-stabilized early, whereas countries that did not deregulate - that is, most of the former Soviet Unionstabilized later. But by the third year of reform, even most of the former Soviet countries had inflation under control. The experience with stabilization and liberalization may introduce a spurious correlation between stabilization and growth. The good growth of the early stabilizers in eastern Europe might be attributed primarily to the reduction of inflation, even if deregulation and depoliticization have been equally important. Conversely, the poor growth of the late stabilizers in the former Soviet Union might be attributed to their failure to reduce inflation quickly enough, even though the real reason is their continued politicization.

Figure 14, which compares inflation in Poland and Russia during transition, shows that Poland had smaller initial inflation and a more rapid disinflation. ${ }^{50}$ But by the fourth year of reform-1994 for Poland and 1996 for Russia-the difference was not large. By early 1997, when reform in the former Soviet countries was entering its fifth year, Russia's annual inflation was below 20 percent. By the end of 1997 , inflation may be even lower in Russia than in Poland. Nonetheless, growth has been much faster in Poland than in Russia.

As of this writing, it is extremely difficult to separate empirically the benefits of stabilization from the benefits of liberalization and deregulation. Time may tell. Meanwhile, some highly preliminary evidence suggests that the effects of depoliticization and institutionbuilding should not be underestimated. For example, panel data regressions (with fixed effects) indicate that in terms of the effect on output, stabilization may be less important than deregulation. Table 9 shows

49. Åslund, Boone, and Johnson (1996)

50. A graph that compared Polish and Ukrainian inflation would look very similar. 
Figure 14. Inflation since Start of Reform, Poland and Russia

Inflation (percent)

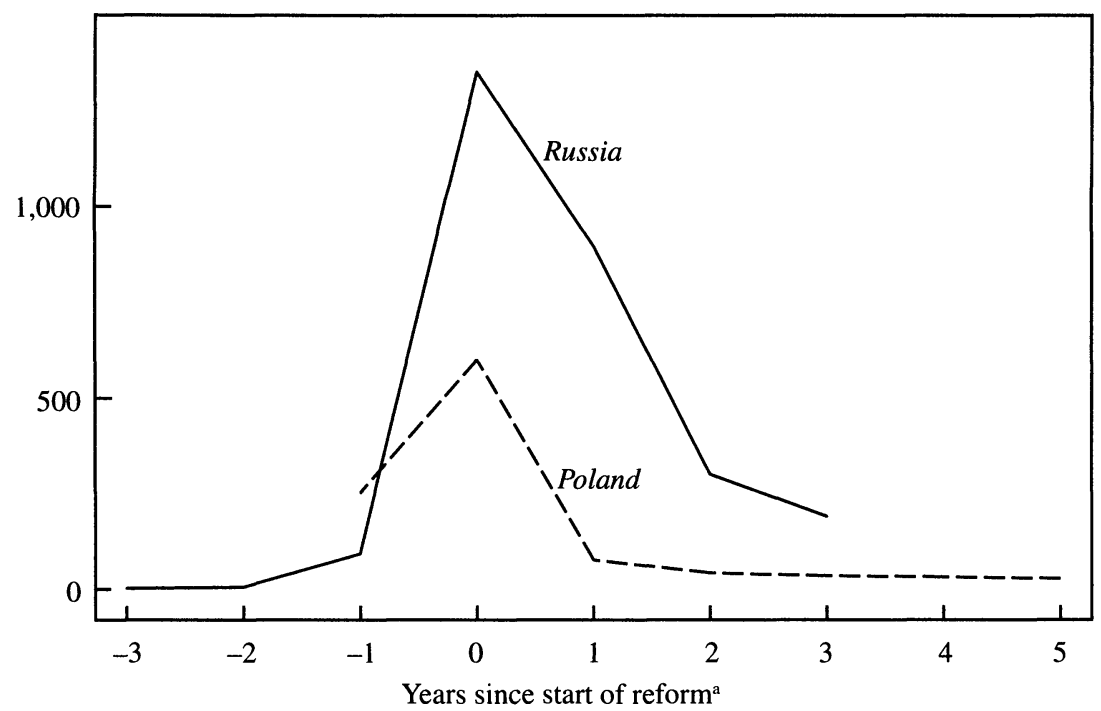

Source: First reform year is the year of most intense reform from Åslund, Boone, and Johnson (1996). For inflation data, see appendix $\mathrm{A}$.

a. Year 0 is the first year of reform: for Poland $1990=0$, for Russia $1992=0$.

the results of regressing total output (official plus unofficial GDP) on log inflation, internal liberalization, and privatization, controlling for the year relative to the start of reform. In some regressions we use the share of the unofficial economy as a proxy for both the extent of regulation and the quality of public goods because we do not have a complete time series for any of the $t$ or $Q$ variables discussed above.

When we run the standard regression for 1989-94 (without the share of the unofficial economy), log inflation is significant at the 10 percent level and privatization is insignificant. Internal liberalization is significant, but has the wrong sign. When we include the share of the unofficial economy on the right-hand side, it has a significant negative coefficient and the other coefficients are not significant. However, when we use the period 1992-95, none of the variables is significant (with the exception of internal liberalization, which has the wrong sign). Overall, the evidence suggests some skepticism about the proposition 
Table 9. Panel Regressions Explaining Total Output in Selected Transition Economies ${ }^{\text {a }}$

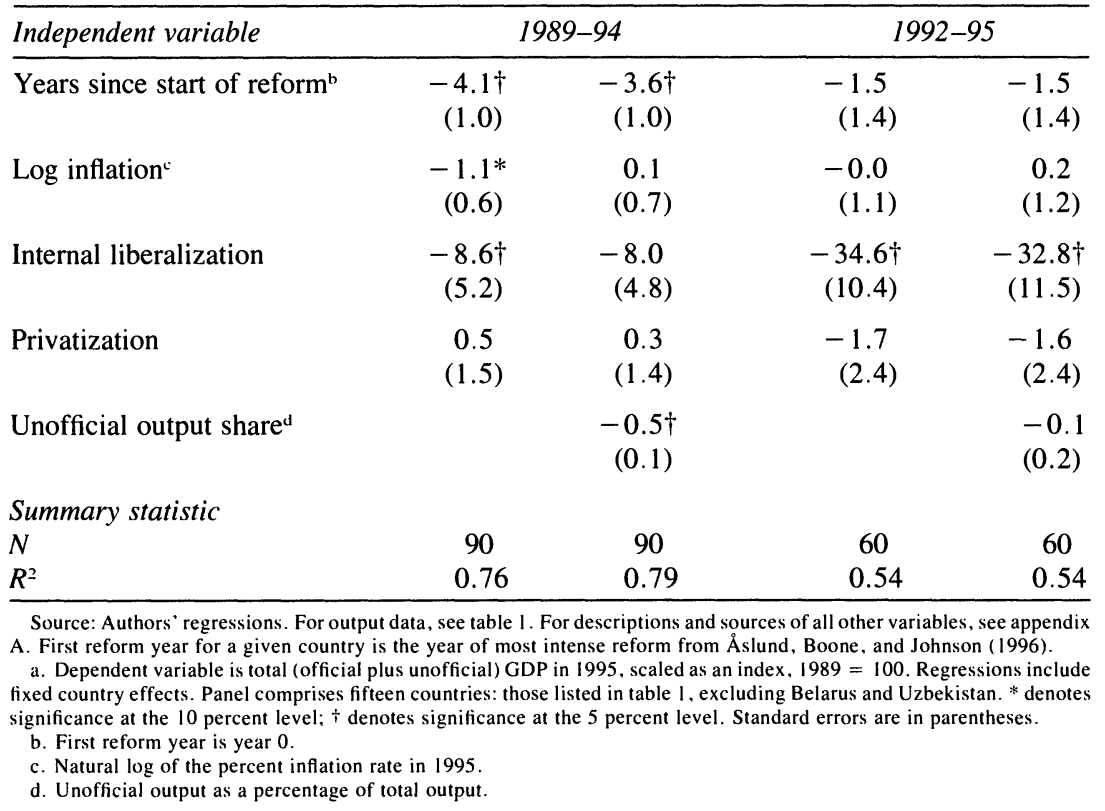

that stabilization can lead to growth without depoliticization and institution-building.

\section{Conclusions and Strategies for Reform}

This paper develops a simple framework for understanding the relationship between taxation and the provision of public goods in an economy, and puts forward several propositions about how tax and regulatory policies affect the relative size of the unofficial economy and economic performance. The economic transition of formerly communist countries since 1989 offers an opportunity to test this theory. The available evidence broadly supports it.

There are three types of transition economies in eastern Europe and the former Soviet Union. First, there are politically repressed economies with highly distortionary taxes, low provision of public goods, but still, a small unofficial sector; Belarus and Uzbekistan are striking 
examples in our sample. Second, there are economies with relatively fair taxes, relatively light regulation, high tax revenues, and relatively good provision of public goods in the official sector; these are concentrated in eastern Europe. Third, there are economies with relatively unfair taxes, relatively onerous regulation, low tax collection, and relatively poor public goods; these are concentrated in the former Soviet Union. Comparing the second and third groups, the former has a lower share of unofficial activity and faster economic growth than the latter.

These findings pinpoint the crucial difference between eastern Europe and the former Soviet Union in the progress of institution-building. It widely agreed that over the next couple of decades, the east European economies will converge to west European living standards. The fate of the economies of the former Soviet Union poses a tougher question. In a pessimistic scenario, they would be stuck in a bad equilibrium for a long time to come, with poor institutions, a large unofficial economy, and an ineffective state. In a more optimistic scenario, appropriate policies would get these countries out of a bad equilibrium and set them on the growth path achieved by the east European countries. The central policy question is how to make the second scenario come true. How can institutions be built in the former Soviet Union?

One strategy is to draw on massive foreign assistance. Indeed, the IMF has played a crucial role in helping Russia achieve macroeconomic stabilization. Nonetheless, foreign assistance has not brought Russia to east European institutional standards. Foreign economic assistance does not, by itself, assure the transition to growth through improvements in the budget situation. This is not a criticism, but rather, a recognition that the political environment can lead to a very poor rate of conversion of money into public goods.

Our analysis suggests that reforms must focus primarily on the elimination of the distortions associated with existing government activities, including tax collection, and on the effectiveness of the conversion of available public revenues into market-supporting public goods. This approach would correspond to an upward shift in the $Q(T)$ function in our model, which, if large enough, can eliminate the bad equilibrium. In the context of Russia, several reforms that correspond to these strategies have been proposed. These include a tax reform aimed at increasing government revenues while reducing marginal tax rates and simplifying tax rules; revision of the federal system, designed to improve the 
incentives of local governments to collect tax revenues and supply public goods; and improvements in the provision of law and order. ${ }^{51}$ Typically, the design of these institutional reforms is not very complicated. The question is whether they are politically feasible.

We believe that there is cause for optimism, at least in some countries of the former Soviet Union-most notably, Russia. One reason is that with privatization and macroeconomic reforms completed, there is relatively widespread agreement about the necessity of institutional reforms. By contrast, in Belarus, Ukraine, Uzbekistan, Tajikistan and Turkmenistan, there is much less support within the elite for essential public finance reforms and deregulation.

In addition, Russia and some other countries in the former Soviet Union, such as Georgia and Azerbaijan, have now achieved a modicum of political stability that could ease the passage of institutional reforms. Boris Yeltsin was reelected President of Russia in 1996, and apparently remains committed to reform. To be sure, the government and the parliament still have major tactical disagreements about particular policies, and there is no guarantee that the institutions that emerge out of the political process will be nearly as market-friendly as those in eastern Europe.

Finally, it is worth noting that institutional reform is possible even in countries with little history of functioning market institutions. Certain East Asian countries have achieved such reforms in relatively short periods of time. In Russia, as well, there have been some considerable successes, such as the creation of a stock market and a legal infrastructure supporting financial markets and institutions. The lack of market history is an impediment to institutional reform, but it is not insurmountable.

To be sure, because so many market-supporting institutions have yet to be set up and because many missteps are likely along the way, we do not expect Russia to achieve spectacular growth in the near future. But it is important to remember that considerable growth is possible without institutional perfection: many east European countries have had their own institutional problems, as do many countries in the West. Reform of the tremendously distortionary tax system will take Russia far along the path of reducing the unofficial sector, increasing govern-

51. For more details, see Shleifer (1997a, 1997b). 
ment revenues, and achieving growth. Russia is moving in the right direction quite rapidly, by both its own and comparative standards. This progress gives cause for cautious optimism about its economic, as well as its political, future.

APPENDIX A

\section{Measures of Reform}

THIS APPENDIX provides descriptions and sources of the various measures of reform that we use in the paper.

Note that although the EBRD indexes are on a scale of 1 to $4^{*}$, there is no apparent reason for using $4 *$ rather than 5. As it says, "most advanced economies would qualify for the $4^{*}$ rating for almost all transition indicators"' (EBRD, 1996, p. 11, n. 1). We convert $4^{*}$ to 5 throughout.

\section{Parameter $\mathrm{t}$}

INTERNAL LIBERALIZATION. Liberalization of "internal markets": price liberalization and elimination of state trading monopolies. Scale is $0-1$, where higher score means more liberalized.

Source: For 1989-94, de Melo, Denizer, and Gelb (1996, sect. 3); updated for 1995 using unpublished data provided by Ratna Sahay of the IMF.

EXTERNAL LIBERALIZATION. Extent of liberalization in "trade and foreign exchange system." Scale is $1-5$. Score is 1 if "widespread import and/or export controls or very limited legitimate access to foreign exchange"; 2 if "some liberalization of import and/or export controls; almost full current account convertibility in principle but with a foreign exchange regime that is not fully transparent (possibly with multiple exchange rates)"; 3 if "removal of most quantitative and administrative import and export restrictions; almost full current account convertibility at a unified exchange rate"; 4 if "removal of all quantitative and administrative import and export restrictions (apart from agriculture) and all significant export tariffs; insignificant direct 
involvement in exports and imports by ministries and state-owned trading companies; no major nonuniformity of customs duties for nonagricultural goods and services"; and 5 if "standards and performance norms of advanced industrial countries: removal of most tariff barriers; membership in GATT/WTO [General Agreement on Tariffs and Trade/ World Trade Organization].",

Source: European Bank for Reconstruction and Development (1995, table 2.1, pp. 11, 12), updated in EBRD (1996, table 2.1, p. 11).

LARGE-SCALE PRIVATIZATION. Extent to which large state-owned firms have been privatized. Scale is $1-5$. Score is 1 if "little progress"; 2 if "comprehensive scheme almost ready for implementation; some sales completed"; 3 if " more than 25 percent of large-scale state-owned enterprise assets privatized or in the process of being sold, but possibly with major unresolved issues regarding corporate governance"; 4 if " "more than 50 percent of state-owned enterprise assets privatized in a scheme that has generated substantial outsider ownership"; and 5 if "standards and performance typical of advanced industrial economies: more than 75 percent of enterprise assets in private ownership with effective corporate governance.'

Source: EBRD $(1995$, table 2.1, pp. 11, 12), updated in EBRD (1996, table 2.1, p. 11).

TAX FAIRNESS. Scale is $0-10$, where higher score means fairer taxes. One of ten dimensions on which a panel of experts graded twenty-six transition countries "for their attractiveness as a place to do business over the coming year." A reasonable interpretation is that the experts took into account both tax rates and the quality of tax administration. For more details, see appendix B.

Source: Central European Economic Review, "The Great Growth Race,' December 1995-January 1996, pp. 8-9, 13 (published as a supplement to the Wall Street Journal Europe).

CRIME AND CORRUPTION. Scale is $0-10$, where higher score means less crime and corruption. One of ten dimensions used to grade twentysix transition countries for their attractiveness as a place to do business over the coming year. For more details, see appendix B.

Source: CEER, "The Great Growth Race,'” December 1995-January 1996, pp. 8-9, 13.

REGULATION. Our scale, which reverses the Heritage Foundation's original scale, is $0-4$, where a higher score means less regulation. Score 
is 4 ("very low") if free of corruption, existing regulations are straightforward and applied uniformly to all businesses, regulations are not much of a burden to business; 3 ("low") if licensing procedure is simple, no bribes, existing regulations are relatively straightforward and applied uniformly most of the time, regulations prove to be a burden to business in some instances; 2 ("moderate") if existing regulations may be applied haphazardly and in some instances are not even published by the government, complicated licensing procedure, regulations are a substantial burden to business, a significant state-owned sector exists, no bribes; 1 ("'high') if government-set production quotas and state planning, major barriers to opening a business, complicated licensing process, very high fees, bribes sometimes necessary, regulations a great burden to business; and 0 ("very high") if government discourages new business creation, bribes mandatory, regulations applied randomly.

Source: Heritage Foundation, published in Johnson and Sheehy (1996).

\section{Variable Q}

LEGAL SAFEGUARDS. Scale is $0-10$, where higher score means better legal safeguards. One of ten dimensions used to grade twenty-six transition countries for their attractiveness as a place to do business over the coming year. For more details, see appendix B.

Source: CEER, "The Great Growth Race," December 1995-January 1996, pp. 8-9, 13.

RULE OF LAW. Scale is $0-10$, where higher score means stronger rule of law. One of ten dimensions used to grade twenty-six transition countries for their attractiveness as a place to do business over the coming year. For more details, see appendix B.

Source: CEER, "The Great Growth Race," December 1995-January 1996, pp. 8-9, 13.

LEGAL EFFECTIVENESS. "The effectiveness of legal rules on investment." Scale is $1-5$. Score is 1 if " legal rules are usually very unclear and often contradictory and the availability of independent legal advice is very limited. The administration of the law is substantially deficient (for example, little confidence in the abilities and independence of the courts, no or poorly organized security and land registers)"; 2 if "legal 
rules are usually unclear and sometimes contradictory. Legal advice is often difficult to obtain. The administration and judicial support of the law is rudimentary"; 3 if "legal rules are reasonably clear and ascertainable through legal advice [but] administrative or judicial support is often inadequate (for example, substantial discretion in the administration of laws, few up-to-date registers); 4 if "law is usually clear and legal advice is readily available. Investment laws are reasonably well administered and supported judicially, although that support is sometimes patchy"; and 5 if "law is clear and readily ascertainable. Sophisticated legal advice is readily available. Investment law is well supported administratively and judicially, particularly regarding the efficient functioning of courts and the orderly and timely registration of proprietary or security interests."

Source: EBRD (1995, table 6.1, p. 103); updated in EBRD (1996, box 2.1, p. 14).

LEGAL EXTENSIVENESS. "The extensiveness of legal rules on investment." Scale is $1-5$. Score is 1 if "legal rules are very limited in scope, and impose substantial constraints on creating investment vehicles, security over assets or to the repatriation of profits. Indirect investment is not specifically regulated"; 2 if "legal rules are limited in scope and impose significant constraints on creating investment vehicles, adequate security over assets, or the repatriation of profits"; 3 if "legal rules do not impose major obstacles to creating investment vehicles and security or to repatriating profits [but] they are in need of considerable improvements"; 4 if "legal rules do not discriminate between foreign and domestic investors and impose few constraints on creating a range of investment vehicles and security instruments. Indirect investment is specifically regulated"; and 5 if "legal rules closely approximate generally accepted standards internationally and impose few restrictions, including on the creation of sophisticated investment vehicles or security. Indirect investment law is well developed.'

Source: EBRD (1995, table 6.1, p. 103); updated in EBRD (1996, box 2.1 , p. 14).

\section{Stabilization Policy}

FISCAL BALANCE. Budget deficit as a percentage of official GDP, calculated using IMF definitions. 
Source: Unpublished data provided by Ratna Sahay of the IMF. Fischer, Sahay, and Végh (1996a, 1996b) use an earlier version of these data

INFLATION. Annual change in the consumer price index (using annual averages).

Source: Unpublished data provided by Ratna Sahay of the IMF. Fischer, Sahay, and Végh (1996a, 1996b) use an earlier version of these data

\section{Political Liberalization}

POLITICAL RIGHTS. "Political rights enable people to participate freely in the political process . . . the system by which the polity chooses the authoritative policy makers and attempts to make binding decisions affecting the national, regional, or local community.' Freedom House's original scale is 1-7 (that is, most liberal to most repressive). We recalculate on a scale of $0-6$, where a higher score is more liberal.

Source: Freedom House, "The Comparative Survey of Freedom 1995-96," pp. 2-3 (available on the Freedom House worldwide web page).

CIVIL LIBERTIES. "The freedoms to develop views, institutions and personal autonomy apart from the state." Freedom House's original scale is $1-7$ (that is, most liberal to most repressive). We recalculate on a scale of $0-6$, where a higher score is more liberal.

Source: Freedom House, "The Comparative Survey of Freedom 1995-96,' ' pp. 2-3 (available on the Freedom House worldwide web page).

POLITICAL PROCESS. "Deals with elections and referenda, party configuration, conditions for political competition, and popular participation in elections.' 'Freedom House's original scale is 1-7 (that is, most liberal to most repressive). We recalculate on a scale of $0-6$, where a higher score is more liberal.

Source: Freedom House, published in Shor (1997).

RULE OF LAW. "Considers judicial and constitutional matters, as well as the legal and de facto status of ethnic minorities.' Freedom House's 
original scale is $1-7$ (that is, most liberal to most repressive). We recalculate on a scale of $0-6$, where a higher score is more liberal.

Source: Freedom House, published in Shor (1997).

\section{The Central European Economic Review Ratings}

IN ITS RATINGS of transition economies, the Central European Economic Review (published as a supplement of the Wall Street Journal Europe) has changed both the composition of its panel of experts and the questions asked over the years. In the February 1995 issue, when these ratings first appeared, the CEER "asked the panelists to rate each of the twenty-five countries on ten categories reflecting their capacity for development through the year 2000. Grades were given on a scale of 0 to 10 , with 10 the highest possible mark, on the basis of the analysts judgment of the countries state five years from now. An average of the results is presented, along with a cumulative average for each country.", The panel comprised Dirk W. Damrau (Salomon Brothers, London), Susanne Gahler (JP Morgan \& Co., London), Andreas Gummich (Deutsche Bank, Frankfurt), Jonathan Hoffman (CS First Boston, London), James Lister-Cheese (Independent Strategy, London), Philip Poole (ING Bank, London), Jan Vanous (PlanEcon, Washington), and Werner Varga (Creditanstalt-Bankverein, Vienna). The ten categories were economic growth, price stability, political stability, currency stability, privatization, infrastructure, productivity, legal framework, trade prospects, and natural resources. Because the panel was looking forward five years, these measures do not seem very reliable as indicators of how the panel viewed the past and current situation, and therefore we do not use any in this paper.

In the December 1995-January 1996 issue, the CEER " asked our panel to rank each of the twenty-six countries on the basis of their attractiveness as a place to do business over the coming year. Grades were given on a scale of 0 to 10 , with 0 the lowest and 10 the highest 
score." On the panel, Peter Havlik (Vienna Institute for Comparative Economic Studies) and Donald Green (PlanEcon, Washington) replaced Philip Poole and Jan Vanous. The ten categories were economic growth, price stability, currency stability, legal safeguards, productivity, infrastructure, ease of portfolio investment, banking system, corruption and crime, and tax burden. Because the questions asked this year were more precise, we use three of these measures: legal safeguards, corruption and crime, and tax burden.

For the December 1996-January 1997 issue, the CEER appears to have made the same general request of the panel as in the previous year: "We asked our panel to rank each of the regions countries on the basis of their attractiveness as a place to do business over the coming year." This panel differed from the previous year's in that Dirk Damrau and Donald Green were replaced by Dan Lubash (Merrill Lynch, London) and Miranda Xafa (Salomon Brothers International, London); thus five of the original 1995 panel remained: Gahler, Gummich, Hoffman, Lister-Cheese, and Varga. Only seven categories were offered: economic growth, price stability, integration into world economy, currency stability, rule of law, ease of portfolio investment, and productivity. Of these, we use rule of law, because it may contain some information that is not revealed in the previous assessments.

APPENDIX C

\section{Alternative Evaluations of the Legal Environment}

SINCE WE ARE particularly interested in the legal environment of reforming countries, it is useful to look at how the various available measures compare in their ratings of countries. An interesting comparison is possible for the countries of the former Soviet Union, in particular, because the IMF provides a measure of institutional development at the end of 1994. This can serve as a cross-check of the indexes that we use in our regressions. Table $\mathrm{C} 1$ compares measures of the legal environment from the IMF, the EBRD, and the CEER.

The IMF ranks countries as having made "low," "medium," or 


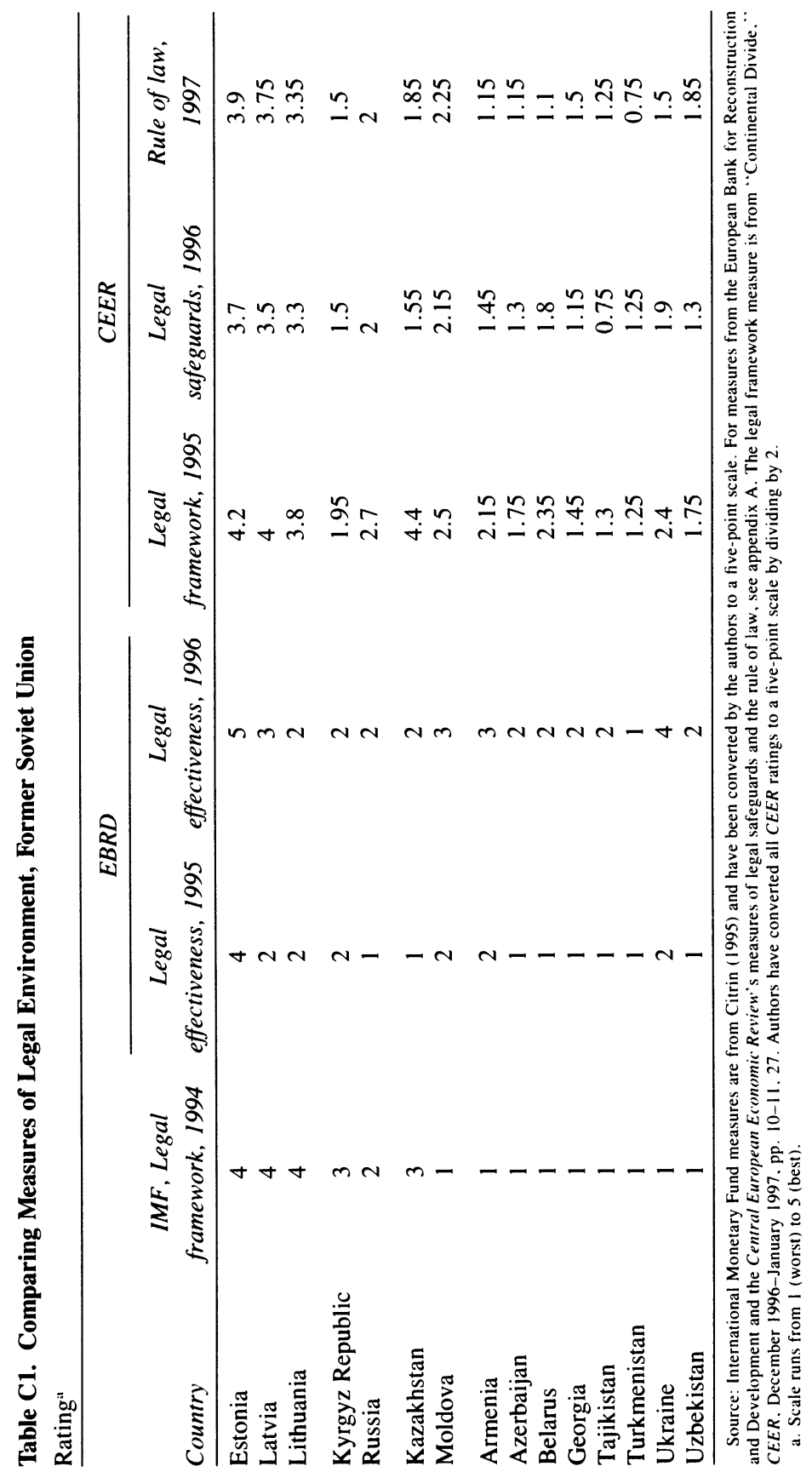


"substantial" progress in terms of fiscal consolidation, privatization and land restitution, government and institutional reform, legal framework, social safety net, and trade liberalization. Intermediate ratings are also allowed (for example, moderate-substantial), so they essentially use a 5 point scale, similar to that of the EBRD.

The EBRD measures are generally well documented and easy to understand. The most notable exception is the case of Ukraine, for which the "legal effectiveness" rating (see appendix A) was increased from 2 to 4 between 1995 and 1996-a surprising shift, not easy to confirm from the EBRD's qualitative assessment.

Table $\mathrm{C} 1$ shows that the IMF ratings clearly differ from those of the EBRD and the CEER. This may be due, in part, to the timing of the evaluations, but it may also reflect unspecified differences in the criteria used. Despite considerable variation in the absolute values assigned, however, the series are quite consistent in terms of the relative rankings of the countries.

\section{APPENDIX D}

\section{General Government Spending}

TABLE D1 reports government spending as a percentage of official GDP as given in European Bank for Reconstruction and Development (1996). Unfortunately, the EBRD does not give these numbers for Russia, but Cheasty and Davis (1996) provide a comparable estimate; the Cheasty and Davis series is similar-generally within 1 or 2 percentage pointsfor almost all the former Soviet countries included in the EBRD series.

The estimates for government spending as a percentage of total GDP are obtained by multiplying the EBRD estimate for each country by our estimate of the share of official GDP in total GDP. 


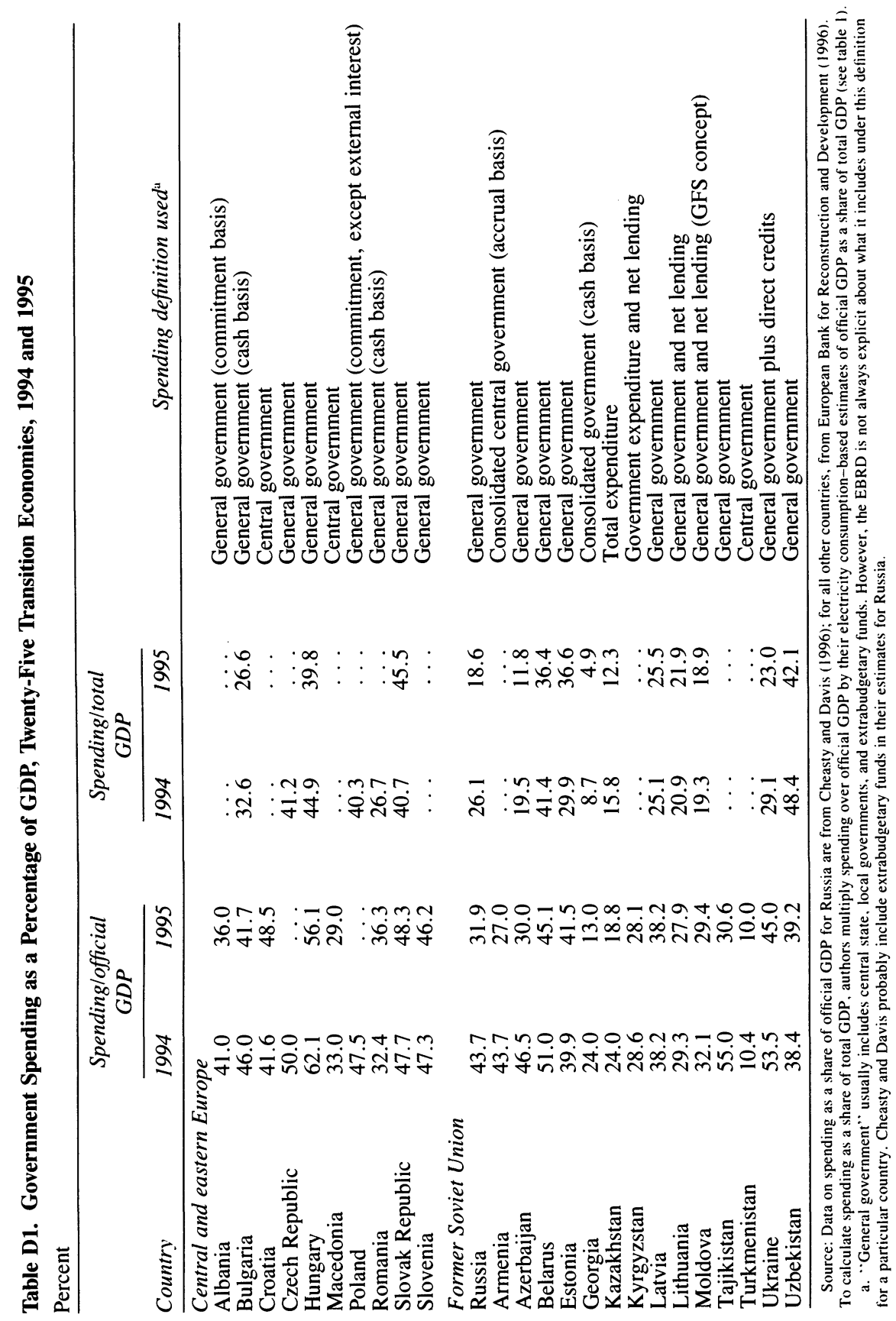




\section{Comments and Discussion}

Marshall I. Goldman: Economists have long recognized the importance of the underground or unofficial economy in capitalist society and sought ways to diminish its role. Simon Johnson, Daniel Kaufmann, and Andrei Shleifer relate these concerns to the transition economies. They argue that the more onerous the taxes and regulations, the poorer the availability of official sector public goods, and the weaker the rule of law, the larger is the unofficial economy. In turn, a large unofficial economy hampers overall economic growth, which spawns an even larger unofficial sector. The depoliticization of economic life is an important step toward creating the proper climate for the formation and operation of legitimate private businesses.

It is hard to take issue with the authors' general conclusions. However, there may well be alternative explanations for some of their findings. I argue for a different approach and try to show that too zealous an effort at depoliticization and too great an emphasis on achieving rapid economic stabilization may be counterproductive and skew the transition process.

In designing their regression, the authors consider various independent variables that undoubtedly do play a role in determining economic growth and driving businessmen to the unofficial economy. However, as an old-time Sovietologist, a much simpler explanation comes to mind: the number of years that a country has spent under communism and whether its culture (a bad word) is supportive or hostile to market activities. The point is illustrated by table E1, which shows annual percentage change in GDP for selected countries in eastern Europe and 
Table E1. Changes in Official GDP, Selected Transition Economies, 1991-96

Percent

\begin{tabular}{|c|c|c|c|c|c|c|}
\hline Country & 1991 & 1992 & 1993 & 1994 & 1995 & 1996 \\
\hline \multicolumn{7}{|c|}{ Central and eastern } \\
\hline \multicolumn{7}{|l|}{ Europe } \\
\hline Bulgaria & -12.7 & -10.7 & 0.8 & 4.2 & 2.4 & -10.1 \\
\hline Czech Republic & . & -4.1 & 1.0 & 5.6 & 5.0 & 4.4 \\
\hline Hungary & -6.8 & -0.6 & 1.3 & 6.1 & 1.5 & 0.6 \\
\hline Poland & -7.6 & 5.3 & 6.1 & 8.3 & 6.5 & 6.0 \\
\hline Romania & -12.9 & -4.9 & 4.3 & 8.6 & 5.4 & 4.1 \\
\hline Slovakia & $\ldots$ & 0.8 & -2.5 & 8.4 & 6.0 & 6.9 \\
\hline \multicolumn{7}{|c|}{ Former Soviet Union } \\
\hline Estonia & -11.0 & & -8.5 & -2.7 & 2.9 & 4.0 \\
\hline Latvia & -10.4 & -34.9 & -14.9 & 6.0 & -1.6 & 2.8 \\
\hline Lithuania & $\ldots$ & $\ldots$ & -30.4 & 1.0 & 2.6 & 3.6 \\
\hline Armenia & -11.7 & -41.8 & -8.6 & 5.4 & 6.9 & 5.8 \\
\hline Azerbaijan & -0.7 & -22.6 & -23.3 & -19.7 & -12.0 & 1.3 \\
\hline Georgia & -21.1 & -44.9 & -29.3 & 8.7 & 3.3 & 11.2 \\
\hline Belarus & -1.2 & -9.6 & -7.6 & -12.6 & -10.4 & 2.6 \\
\hline Kazakhstan & -11.0 & -5.3 & -10.6 & -12.6 & -8.2 & 1.1 \\
\hline Kyrgyzstan & -7.8 & -13.9 & -15.6 & -20.1 & -5.4 & 5.6 \\
\hline Moldava & -17.5 & -29.0 & -1.2 & -30.9 & -1.9 & -8.0 \\
\hline Russia & -5.0 & -14.5 & -8.7 & -12.6 & -4.1 & -4.9 \\
\hline Tajikistan & $\ldots$ & $\ldots$ & -17.3 & -12.7 & -12.4 & -16.7 \\
\hline Turkmenistan & $\ldots$ & $\ldots$ & 7.8 & -24.0 & -10.0 & 0.1 \\
\hline Ukraine & -8.7 & -9.9 & -14.2 & -22.9 & -12.8 & -10.0 \\
\hline Uzbekistan & -0.5 & -11.1 & -2.3 & -4.2 & -1.2 & 1.6 \\
\hline
\end{tabular}

Source: Author's calculations based on data from U.S. Central Intelligence Agency (1996); World Bank (1996a); and "Economies of Countries of the CIS." a document available to subscribers on the worldwide web page of Internet Securities, 1997.

the former Soviet Union. The various reporting agencies offer different estimates of GDP growth, but these do not seem to affect the overall trends. The countries surveyed fall into three distinct groups. In the first are the countries of central and eastern Europe, almost all of which began to report positive economic growth in 1993, three years (in the case of Poland, two years) after the start of reform. These countries endured at most forty-five years of communism.

The second category includes the former Soviet republics in the Baltic and Caucasus regions. Although a bit more erratic, their economic growth began in 1994. The Baltics had communist regimes for approximately as long as did eastern Europe. The three countries of the Caucasus were communist for seventy years, but there is general agree- 
ment that throughout the period the underground economy was much more active in this region than almost anywhere else in the former Soviet Union. Traders selling regional products often came to dominate collective farm markets in other parts of the Soviet Union. The fact that the climate in the Caucasus is well suited to growing vegetables and fruits provided traders from this region with an important advantage. As a consequence, the culture-or ethos-of the Caucasus encompassed relatively more nonstate economic activity, both unofficial and legal.

The third category comprises all the Slavic and the Central Asian countries from the former Soviet Union. With the exception of Moldava, these were communist for at least seventy years and, with the exception of a single year in Turkmenistan, all had negative rates of growth from 1991 through 1995. In some-including Russia and Ukraine-GDP will continue to decline through 1997, five to six years after the start of reform and four to five years after the turnaround in eastern Europe. In other words, the longer a country was ruled by the communists, the longer it takes to recoup and resume economic growth.

This simple variable may be as, or more, powerful a predictor than those used by the authors in their more complicated model. There are several reasons for this. After the collapse of the communist governments in eastern Europe, familiarity with market ways of doing business, for the most part, was easily and quickly reestablished. Forty-five years had been a long time, but there were still many who remembered how the old system operated. For that matter, in the communist era several of the east European countries took a more benign attitude toward the market, private farms, and private business than did the Soviet Union. In the extreme case of Poland, 80 to 85 percent of the farms were never collectivized, and the state always allowed a small private service sector. Even though not everyone in eastern Europe could engage in market activities for themselves, because of their proximity to the West they could more readily observe the nuances of the market. The additional twenty-five years of communist control in the Soviet Union destroyed virtually all memory and institutional remnants of the previous economic system and made the restoration of market infrastructure significantly more difficult and time-consuming. (In their discussion of control variables, the authors do acknowledge the dam- 
age done in countries that had an additional generation of communist government.)

Table E1 also has some important implications for the depoliticization of the economy. In principle, there is no quarrel with depoliticization that brings "regulatory and tax relief, reduction in corruption [and] the elimination of subsidies." However, in the countries where communism lasted the longest, it has been essential not only to destroy (depoliticize) some controls and taxes, but at the same time or even earlier to construct (politicize) a market infrastructure. Because destruction of the market environment was so much more thorough in the Soviet Union-indeed, the market was not all that well developed under the czars - the reform process under Yeltsin began in a near vacuum. ${ }^{\prime}$ There were no commercial codes, bankruptcy laws, commercial courts, judges, or market accounting standards, nor the informal behavior patterns that temper the extremes of the unfettered market. More important, there were no competitive markets. Before businesses can operate normally and before governments can provide the services that authors feel are necessary, these institutions have to be reestablished.

Not all of these elements were present in eastern Europe either (although many were), but given the memory of institutions past, those that had existed previously were reconstituted with relative ease. It was a serious mistake-if not folly-to ignore the lack of any such preexisting infrastructure in most of the former Soviet Union, or to assume that it could be quickly created simply by privatizing state industry. It is true that "the Russian people, like the rest of the people in the world, [are] 'economic men' who rationally [respond] to incentives,' ' and they are not lacking in entrepreneurial ability. ${ }^{2}$ But if there is no market infrastructure, no market competition, and none of the checks and balances that evolve over the years to temper the economic dominance of one group or another, then economic men, including Russians, will act in asocial ways-particularly so if the reform process does not anticipate and seek to mitigate their excesses.

In retrospect, one should not have been surprised by the growth of the mafia in the former Soviet Union, nor of bandit capitalism so un-

1. On the czarist era, see Owen (1991, p. 209).

2. Boycko, Shleifer, and Vishny (1995, p. 9). 
controlled that one leading banker-politician has asserted that seven bankers control 50 percent of the country's economy. ${ }^{3}$ A bit exaggerated perhaps, but not too far from the mark if one includes the directors of Gazprom, the world's largest gas producer, and Lukoil, with oil reserves greater than those of Exxon. To privatize the larger monopolistic state enterprises in the absence of prophylactic mechanisms, such as market competition or effective antitrust legislation, was like importing the melaleuca, an Australian tree, to dry out part of the Florida Everglades. ${ }^{4}$ Without the natural predators that contain its growth in Australia, this tree, like the privatized monopolies and big bankers in Russia, has threatened to overwhelm its new environment. The melaleuca already covers about 7 percent of the Everglades.

In much the same way, the seven bankers are using their control not only of so much of the economy but also of the media to bully government officials at the very highest level. Allied for a time, these bankers are now feuding among themselves and, in the process, resurrecting old Soviet techniques of slander-and on occasion, physical intimidation. When added to the pervasive role of the mafia, a capricious tax system, and corrupt government officials, these practices have made it more difficult to start new businesses in the former Soviet Union than it was five years ago.

As important as it may be to privatize state enterprises, even higher priority should be given to fostering the growth of new start-up traders, farmers, and businesses. Simultaneously, commercial codes, laws, and courts should be reinvented. But that is not enough. The hard part is to ensure that the laws and codes become operational. In the best case of transition, the emphasis in Poland was on start-ups and the development and implementation of new behavioral codes; in the former Soviet Union (Russia, in particular) the emphasis was on privatization and the passage of, but not adherence to, new laws. This is one of the major reasons why the mafia and business monopolies are so much less dominant and adherence to codes and the law is so much more prominent

3. The banker-politician is Boris Berezovsky, in Chrysta Freeland, John Thornhill, and Andrew Gowers, “Moscow's Group of Seven: Chrysta Freeland, John Thornhill, and Andrew Gowers on the Business Leaders Shaping Russia's Future,' Financial Times, November 1, 1996, p. 17.

4. Mireya Navarro, "U.S. Dispatches an Army of Tree-Hungry Beetles to Fight Everglades Menace,'” New York Times, May 4, 1997, p. 22. 
in Poland and most of the rest of eastern Europe than it is in Russia and the rest of the former Soviet Union. ${ }^{5}$

The overriding fixation with privatization in the former Soviet Union has, in some ways, been matched by a fervent determination to halt inflation. The authors note that in Russia stabilization did not bring with it the economic recovery that it did in eastern Europe. They caution that it is difficult to determine whether the failure to grow is due to stabilization policy (perhaps too slow) or depoliticization and deregulation (not far reaching enough). I would argue that, as in the case of privatization, there was too much emphasis on tight money and credit at a time when existing rules and regulations were either inadequate or nonfunctioning. The absence of meaningful bankruptcy procedures has been particularly important. High real interest rates have been a factor in the cash crisis that prevails throughout the former Soviet Union, the continuing decline in direct capital investment, and the growth of the banking giants (I would hate to think what might have happened if the effort to reduce inflation had been even more draconian).

I also have some comments about the authors' regression model. First, they surely do not want more $Q$ (the quantity of the public good), as they seem to indicate in equation 1 . Even if it is assured that this would bring good government, it would also mean big government, which would crowd start-ups in the private sector.

Second, the authors assume that all the political institutions described in appendix A are in place. However, that does not necessarily mean that they are commonly accepted or part of the culture. Similarly, while the emphasis on depoliticization evidenced in this appendix is to be applauded, politicization is necessary as well in those countries where the market framework and its formal and informal codes must be refurbished or reintroduced.

Third, a variable that is important in explaining economic growth, or its absence, is the level of prereform expenditures on the militaryindustrial complex. Such expenditures were high throughout the communist bloc, and especially so in the former Soviet Union where, according to Mikhail Gorbachev, military expenditures constituted 20 percent of GNP during the 1980 s. ${ }^{6}$ In consequence, conversion has

5. Frye and Shleifer (1997, p. 357).

6. Gorbachev (1996, p. 215). 
been very difficult for the countries of the former Soviet Union; in particular, for Russia, where the proportion of industry dedicated to military production under communism in many cities exceeded 50 percent-in Irkutsk, for example, it may have been as high as 80 percent. Slashing budget expenditures has posed an additional burden on those areas, which helps to explain why Moscow grew at close to 10 percent a year in 1996, while Novosibirsk was shrinking by 15 percent a year. The authors recognize the extraordinary role played by the militaryindustrial complex, and that its sudden contraction can result in "disruption of trade." More important, it also led to a sudden collapse of industrial production that is not explained by the variables that the authors use to understand relative differences in the recovery of GDP.

Fourth, Belarus and Uzbekistan do not seem to fit the model comfortably. The authors speculate that this may be due to the repressive nature of the regimes in these two countries. Specifically, they suggest that repression may explain the lack of activity in the unofficial sector. That may be true about Belarus, which has not been noted as a center of either official or unofficial trade. However, it is not true of Uzbekistan, which was a center of unofficial trading in the prereform era and, from most reports of visitors to the region, continues to be. Thus there is a strong likelihood that the Uzbek data used by the authors is inaccurate, or that Uzbekistan presents a very different situation, or both.

Fifth, the model also suggests that if a government is weak, mafiatype operations may come to dominate, so that the unofficial sector is able to protect itself and generate increasing returns. The implication is that there is then no limit to such growth. But this ignores the restraint that such a regime would most likely encounter from international sources. That is not to say that there could never be a bandit regimeonly that its growth would sooner or later be circumscribed by outside pressures. Likewise, a good government that manages to hold down the unofficial sector will still face random acts from mafia groups. It is hard to find governments in the world today, even the best run, that have eliminated all mafia-type activities.

Sixth, the authors recognize the difficulty of determining whether to use a unit elasticity calculation or one that is higher or lower. To complicate their task, it seems likely that to the extent there are new business start-ups in the former Soviet Union, these will be more effi- 
Table E2. Changes in Electricity Usage and Official GDP, Russia, 1991-96

Percent

\begin{tabular}{lcccccc}
\hline Item & 1991 & 1992 & 1993 & 1994 & 1995 & 1996 \\
\hline Electricity usage & -1.3 & -5.7 & -5.1 & -8.5 & -1.8 & -1.5 \\
Official GDP & -5.0 & -14.5 & -8.7 & -12.6 & -4.1 & -4.9 \\
\hline
\end{tabular}

Source: Author's calculations. Electricity data for 1991-95 are from Goskomstat Rossii (1996); for 1996, from the worldwide web page of Goskomstat Rossii. GDP data are from table El

cient than the former state enterprises, so that an elasticity of less than one might be more suitable.

Finally, the authors take electricity generation as a more accurate measure of overall output, but this does not lead to the conclusion-at least, not for Russia-that GDP has been increasing. As table E2 indicates, Russian electric power has declined each year since 1991, although generally by less than GDP. In the first half of 1997, however, electricity generation dropped by 4.4 percent, whereas the decline in GDP was only 0.2 percent.

The authors conclude that unfair taxation and heavy regulation cause the unofficial sector to grow, and that this leads to low tax collections and poor public goods in the official sector, which together impede economic growth. However, that should not blind one to even more basic considerations that are crucial to the transition process. The purposeful attack on market institutions for over seventy years in most of the former Soviet Union meant that those countries began the transition process a full stage of development behind most of eastern Europe. A completely new institutional, legal, and competitive framework has to be reinvented before healthy growth can be expected. Moreover, not only is depoliticization of the economy a necessary prerequisite for growth, so is politicization-that is, the creation and establishment of a traditional market and legal framework. The failure to recognize such a first step has resulted in what some have described as bandit capitalism. While there have recently been signs that some new leaders are determined to correct some of the grosser excesses, their task will not be easy, to say the least. Undoing the damage wrought by the mistaken policies that were initially adopted may prolong the process.

Future historians looking back at the transition process in the countries of the former Soviet Union may consider that the extra three or 
four years that they needed was, after all, a relatively short time. That may be so. However, even if Ukraine and Russia do begin to grow at a healthy rate, they will be left with a legacy of theft and criminality in the business sector and the feeling that the population has suffered. These matters are certain to haunt the reform effort for years to come.

Martin L. Weitzman: This ambitious study has, as most ambitious studies do, a theoretical model as its centerpiece. In broad generic terms, this paper's model is of the increasing returns, multiple equilibria, big push form. There are essentially two kinds of competition. "Good" competition is identified with a small unofficial economy, whereas "bad" competition occurs when there is a large unofficial economy. Although this part of the model is not really spelled out precisely, bad competition is bad and good competition is good because the official sector is presumed to be more productive at generating public goods than the mafia.

The model is so constructed that an economy can either be in a " "good" equilibrium with good competition or be in a "bad" equilibrium with bad competition. The good equilibrium is a virtuous circle, in which the government offers a sufficiently attractive combination of tax rates, regulations, and public goods that a preponderance of firms chooses to stay in the official sector, thereby generating a source of government tax revenues to provide the public goods and allow the government to outcompete the unofficial sector-a postitive feedback system. Conversely, a bad equilibrium is a vicious circle, in which the government cannot offer a sufficiently attractive combination of tax rates, regulations, and public goods to make it in firms' self-interest to operate in the official sector, and so they move to the unofficial sector, thereby completing the negative feedback loop by denying the government sufficient tax revenues.

Which equilibrium an economy ends up in depends on initial conditions and what is assumed about the underlying dynamic adjustment mechanism. But whatever the initial conditions and economic dynamics, the model predicts certain correlations between variables that are endogenously determined by whether they are in a good or in a bad equilibrium. Johnson, Kauffman, and Shleifer look at transition as a kind of natural experiment, where a number of countries were cut loose from central planning and sorted themselves-or more accurately, were 
sorted by history-into one of the two equilibrium states. A test of the theory would then be to look at the data and see if the predicted finalstate correlations have actually occurred.

This suggests one problem right away. In the pure model of this framework, there are no genuine exogenous differences. All countries are essentially identical; they just happen to end up in one of the two equilibria, according to their initial conditions and dynamic adjustment mechanisms. But suppose that there are exogenous differences between countries. Suppose that one cannot observe or quantify these exogenous differences very well, but that they are correlated in a complicated way with the supposedly endogenously determined differences, which one can observe. Suppose, also, that rather than only two possible discrete equilibria, there is (more realistically) a continuum of equilibria. Then it is a potentially very messy statistical problem to unscramble whether the theory holds, because one could be seeing associations among the observed variables that are formed for reasons other than those predicted by the theory. My sense is that in this case the data are replete with such problems. The authors make a brave attempt at inserting dummy variables strategically, but I wonder how much action this picks up and how legitimate it is statistically, done on such an ad hoc basis.

Even without this problem of identifying the source of variation, the authors are faced with a statistical headache of enormous magnitude. Most of the predictions involve, either directly or indirectly, variables that are nonstandard in one way or another: the size of the unofficial economy, the degree of corruption, the legal environment, and so forth and so on. This is not the fault of the authors; the area is just very difficult to research. As one example, take the share of the unofficial economy. The authors use some very rough estimates to fix initial levels and then use an electricity-consumption-based methodology to track changes across time.

It would be easy to spend time taking potshots at this kind of methodology because it offers a big, fat target. The real questions here are, first, what are the alternatives? And second, when all is said and done, can anything meaningful be salvaged from what seems like a statistical morass?

The first question is easy to answer, because there is no good quantitative alternative. The qualitative alternative is to look at things a bit more informally, as a good historian might. I return to this line below. 
The second question is more difficult. Given all of the data problems and given the misspecifications of multicausal links that are undoubtedly rampant in an exercise of this nature, can one confidently conclude anything about causality here from running a lot of regressions? I fear that this kind of study may be very close to the edge. The authors conclude that the available evidence broadly supports the model framework, but I am really not sure whether I would believe this on the basis of the regressions that they run.

What do researchers in other fields do when confronted with important questions that are difficult to answer cleanly because the world is a multicausal mess and the right data are not available? The best analogy that I can think of is in the field of medical statistics. There are thousands of striking patterns in the incidence of disease that no one can fully explain. For example, there is apparently a statistically significant correlation between household ownership of microwave ovens and the incidence of cataracts, which remains even after controlling for the few other household variables for which data also exist. It could be that microwave use is some kind of a causal agent for cataracts, or that people who are prone to be diagnosed with cataracts are more likely to own microwave ovens for some as-yet-unknown reason whose causal mechanism is hidden. No one is sure. In such a case, I think that if the result holds up when one throws whatever other variables one has on one's data tape into the regressions, and if it fits in with one's preconceived notions of what might be going on, one warns the public to be cautious about staring into a working microwave oven from half an inch away.

I guess the same strategy applies in this study of the unofficial economy in transition. One is told that the results do not come apart under alternative specifications or when using somewhat different data. That is, what might better be called the controlled correlations in this study are supposed to be stable. (I take the authors' word on this important aspect, since only they can know.) At a high level of abstraction, the model and most of the controlled correlations fit in with my preconceived notions of what is going on. So, I am probably more inclined to believe than to disbelieve the results. But convincing econometricseconometrics that convincingly establishes causality - this is not.

I do believe that the spiritual message of this paper is both correct and very important. The "good" form of capitalism (that with good 
competition) is a kind of global optimum that is not, however, globally stable along the way. That is, if one gets there one is better off than in the alternative; but to do so one has to follow a particular path, along which one will not necessarily be improving every step of the way, nor be better off than the alternatives every step of the way. To see why this may be so, look back to the original " transition,"' when capitalism emerged from feudalism.

The OECD-level countries at present consist of western Europe; former British colonies, where the native population was suppressed or was numerically insignificant to begin with; and Japan. That is, with the exception of Japan (and leaving aside the oil kingdoms), all the rich countries today are European or derived from Europe. The rise of the West is a great theme of history and a major puzzle. In the Middle Ages, the technological prowess and standards of living of Europe did not much impress those foreign observers who left a written record, such as traveling Arab merchants. On the contrary, medieval European travelers were often awed by what they saw in Asia, as was Marco Polo in China. Why did Europe grow so rapidly relative to everywhere else? The most immediate answer is capitalism. Yet this raises the further questions of how capitalism came into being and why it took root so deeply in Europe but not elsewhere.

Capitalism elevates to high status the concept of cut-throat competition within the overall framework of the rules of the game. It is perfectly all right for a man to ruin his neighbor by competing vigorously in the marketplace-indeed, he may become a cultural herobut it is illegal to achieve the same effect with a gun or a knife. While this system may seem natural to those who have grown up with it, it is far from natural to outsiders. Capitalism encourages aggressive warlike behaviors within the arena of the private economic sector (as demarcated from on high, sometimes somewhat arbitrarily) but at the same time attempts to strictly confine this aggressive behavior and prevent it from spilling over into any other sector of society. The overall verdict of history is that this unlikely sounding combination can make an incredibly productive system, more productive than any other that has been tried.

The capitalist system is a two-ring circus. In ring one are the lions of capitalism-competitive, aggressive, mean-spirited. In ring two are the lambs that represent good government, a civil society, and a kinder, 
gentler life. The circus act is better when the lions are pumped-up and really hungry. But this sets up a tension, because the hungry lions are not supposed to cross over the line drawn in the sand, separating them from the lambs resting in ring two. It is an implausible, potentially explosive, contradictory situation when a society wants a ring full of ferocious lions but expects them not to transgress the weak and seemingly artificial boundary on the circus floor.

As to how such a peculiar and contradictory system came into being, I think it is no coincidence that Europe and Japan share a feudal past, with castles, knights in armor, tournaments, codes of chivalrous behavior, and all the other trappings. For the purposes of this discussion, feudalism is a highly ritualized system that, rather than outlawing private armies and regional warfare (as would a centralized despotism), evolves elaborate rules of the game that allow such warfare but limit its potential for devastation through strict taboos on particularly egregious forms. To take an example from Japan, while almost all manner of cruelty was sanctioned in feudal warfare, using fire was forbidden, since otherwise the wooden buildings that were widespread in Japanese cities and villages at the time might be burned to the ground. European feudal codes also tolerated unbelievably cruel forms of private warfare, but they forbade attacks on women and children. These feudal systems did not appear particularly productive when contrasted with contemporary oriental despotisms, but they contained the primitive seeds of an idea that was destined to become enormously productive: that a community might allow, even encourage, aggressively competitive behavior, provided that such behavior is kept within certain demarcated channels.

The basic idea here is that feudalism served as a kind of kindergarten for capitalism. Without such an early schooling, it is difficult for a society to grasp the essential idea of capitalism and obtain the good kind of competition. Lacking this basic training, societies tend either to veer off into mafia-like disregard of all boundaries-which represents excessive competitive warfare-or to succumb to excessive centralized despotism with not enough competitive warfare. It is hard to get the right balance by going only to grade school; it helps greatly to have attended some preschool socializing sessions, where students learn how to play, and fight, by the rules.

To return to the unofficial economy in transition, I am extremely 
sympathetic with the aims of this paper. Like the first transition to capitalism, the post-Soviet experience shows that the establishment of good competition is the single most important aspect of transition. But it also shows that it is difficult to attain equilibrium with good competition, a task far transcending in its challenge the traditional supplyand-demand-type instruments in the standard toolkit of the economist.

General discussion: Alberto Alesina suggested that it would be useful to distinguish between two types of vicious circle that could expand or perpetuate the unofficial economy. In an economic circle, high tax rates create a large unofficial sector, which creates low tax revenues and requires still higher tax rates. In a rule of law circle, which may be more damaging in the long run, there is little rule of law to start with when the unofficial sector emerges, and the expansion of the unofficial sector adds to its acceptability, further undermining the rule of law. $\mathrm{He}$ noted that an economic circle should be more susceptible to narrowly economic remedies, such as lower tax rates. Shleifer replied that cultural entrenchment of tax avoidance did not seem to be a major problem. For example, in several Latin American countries once tax codes were simplified, revenues increased dramatically. However, Alesina noted that tax avoidance varied considerably even across OECD economies and offered a rough estimate that Italy's debt-to-GDP ratio today would be only 60 to 80 percent rather than 120 percent if it had been enjoying the same tax compliance as the United States.

Alan Auerbach observed that if the adequacy of public goods determines whether a country ends up at a good or a bad equilibrium, and if tax resources are currently too limited to achieve adequacy, then an appropriate policy response would be to borrow internationally in order to finance the level of public goods needed to keep the unofficial sector small. Shleifer replied that not all tax revenues are used in socially beneficial ways, and funds from foreign borrowing presumably would not be either. Institutional reforms are needed to improve the provision of law and order, to support financial markets, and to reduce tax disincentives in the official sector.

Olivier Blanchard raised questions about the model's predictions for how the official and unofficial economies would evolve over time. If the evolution depended on whether businesses preferred mafia enforcement or government enforcement-either because one was more pro- 
ductive than the other or for other reasons-knowing more about those preferences would be important for predicting or affecting outcomes. He suspected that local firms might be content with mafia enforcement, whereas larger firms, and especially foreign firms, would prefer government enforcement. In this case, foreign direct investment might be key to the expansion of the official sector. Robert Hall noted that a number of previous studies had analyzed the importance of institutions and used the framework of good and bad equilibria. The standard finding is that law-based, above ground economies are more productive. He observed that the empirical work in this paper, which found little difference in the performance of the official and unofficial sectors, stood in stark contrast with these other results. Shleifer responded that the paper's inconclusive findings about relative performance in the two sectors should not be extrapolated from the transition economies to more advanced economies. There, he agreed, the evidence does suggest that a country benefits from strong institutions supporting the official economy. 


\section{References}

Åslund, Anders, Peter Boone, and Simon Johnson. 1996. "How to Stabilize: Lessons from Post-communist Countries." BPEA, 1:1996, 217-313.

Blanchard, Olivier J. 1997. The Economics of Post-Communist Transition. Oxford University Press.

$\rightarrow$ Blanchard, Olivier J., and Lawrence H. Summers. 1987. "Fiscal Increasing Returns, Hysteresis, Real Wages and Unemployment." European Economic Review 31(3): 543-66.

Boycko, Maxim, Andrei Shleifer, and Robert W. Vishny. 1995. Privatizing Russia. MIT Press.

$\longrightarrow \rightarrow \cdot$ 1996. "A Theory of Privatization." Economic Journal 106(435): 309-19.

Brunetti, Aymo, Gregory Kisunko, and Beatrice Weder. 1997. "Institutions in Transition: Reliability of Rules and Economic Performance in Former Socialist Countries.' Policy Research Working Paper 1809. Washington: World Bank (August).

Citrin, Daniel A. 1995. "Overview." In "Policy Experiences and Issues in the Baltics, Russia, and Other Countries of the Former Soviet Union, '” edited by Daniel A. Citrin and Ashok K. Lahiri. Occasional Paper 133. Washington: International Monetary Fund (December).

Cheasty, Adrienne, and Jeffrey M. Davis. 1996. "Fiscal Transition in Countries of the Former Soviet Union: An Interim Assessment." Working Paper 96/61. Washington: International Monetary Fund (June).

de Melo, Martha, Cevdet Denizer, and Alan Gelb. 1996. "From Plan to Market: Patterns of Transition." Policy Research Working Paper 1564. Washington: World Bank (January).

de Melo, Martha, and others. 1997. "Circumstance and Choice: The Role of Initial Conditions and Policies in Transition Economies." Unpublished paper. World Bank (August).

de Soto, Hernando. 1989. The Other Path: The Invisible Revolution in the Third World. Translated by June Abbott. Harper and Row.

European Bank for Reconstruction and Development. Various years. Transition Report. London.

Fischer, Stanley, Ratna Sahay, and Carlos A. Végh. 1996a. "From Transition to Market: Evidence and Growth Prospects." Unpublished paper. Washington: International Monetary Fund (August).

$\rightarrow$ - 1996b. "Stabilization and Growth in Transition Economies: The Early Experience." Journal of Economic Perspectives 10(2): 45-66.

Freund, Caroline L., and Christine I. Wallich. 1995. "Raising Household Energy Prices in Poland: Who Gains? Who Loses?' Policy Research Working Paper 1495. Washington: World Bank (August). 
Friedman, Eric J., and Simon Johnson. 1996. "Complementarities and Optimal Reform." Unpublished paper. Duke University (November).

Frydman, Roman, and Andrzej Rapaczynski. 1991. "Markets and Institutions in Large-Scale Privatization: An Approach to Economic and Social Transformations in Eastern Europe." In Reforming Central and Eastern European Economies: Initial Results and Challenges, edited by Vittorio Corbo, Fabrizio Coricelli, and Jan Bossak. Washington: World Bank.

$\rightarrow$ Frye, Timothy, and Andrei Shleifer. 1997. "The Invisible Hand and the Grabbing Hand.' American Economic Review, Papers and Proceedings 87(2): 354-58.

Gorbachev, Mikhail. 1996. Memoirs. Doubleday.

Goskomstat Rossii. 1996. Rossiiskii Statisticheskii Ezhegodnik. Moscow: Logos.

Gray, Dale. 1995. "Reforming the Energy Sector in Transition Economies: Selected Experience and Lessons."' Discussion Paper 296. Washington: World Bank.

$\rightarrow$ Grossman, Sanford J., and Oliver D. Hart. 1986. "The Costs and Benefits of Ownership: A Theory of Vertical and Lateral Integration." Journal of Political Economy 94(4): 691-719.

Hellman, Joel. 1996. "Competitive Advantage: The Politics of Stabilization in Postcommunist Transitions." Unpublished paper. Harvard University.

Johnson, Bryan T., and Thomas P. Sheehy, editors. 1996. 1996 Index of Economic Freedom. Washington: Heritage Foundation.

Johnson, Simon, and Gary Loveman. 1995. Starting Over in Eastern Europe: Entrepreneurship and Economic Renewal. Harvard Business School Press.

Kaufmann, Daniel. 1994. "Market Liberalization by Stealth-Curse or Blessing in Disguise?"' In Trade in the New Independent States, edited by Constantine Michalopoulos and David G. Tarr. Washington: World Bank.

1997. "The Missing Pillar of a Growth Strategy for Ukraine: Reforms for Private Sector Development." In Ukraine: Accelerating the Transition to Market, edited by Peter K. Cornelius and Patrick Lenain. Washington: International Monetary Fund.

Kaufmann, Daniel, and Aleksander Kaliberda. 1996. "Integrating the Unofficial Economy into the Dynamics of Post-Socialist Economies: A Framework for Analysis and Evidence." In Economic Transition in Russia and the New States of Eurasia, edited by Bartlomiej Kaminski. Armonk, N.Y.: M. E. Sharpe.

Kaufmann, Daniel, and Paul Siegelbaum. 1997. "Privatization and Corruption in Transition Economies." Journal of International Affairs 50(2): 419-58.

Leitzel, Jim. 1995. Russian Economic Reform. London: Routledge.

Loayza, Norman V. 1996. "The Economics of the Informal Sector: A Simple 
Model and Some Empirical Evidence from Latin America." CarnegieRochester Conference Series on Public Policy 45: 129-62.

Owen, Thomas C. 1991. The Corporation Under Russian Law, 1800-1917: A Study in Tsarist Economic Policy. Cambridge University Press.

Sachs, Jeffrey D. 1995. "Russia's Struggle with Stabilization: Conceptual Issues and Evidence." In Proceedings of the World Bank Conference on Development Economics 1994, edited by Michael Bruno and Boris Pleskovic. Washington: World Bank.

Sachs, Jeffrey D., and Andrew M. Warner. 1996. "Achieving Rapid Growth in the Transition Economies of Central Europe." Working Paper 116. Stockholm Institute of East European Economies (November).

Shleifer, Andrei. 1997a. "Agenda for Russian Reforms." Economics of Transition 5(1): 227-31.

- 1997b. "Joseph Schumpeter Lecture: Government in Transition." European Economic Review 41(3-5): 385-410.

$\rightarrow$ Shleifer, Andrei, and Robert W. Vishny. 1993. "Corruption." Quarterly Journal of Economics 108(3): 599-617.

$\rightarrow \rightarrow$ 1994. "Politicians and Firms." Quarterly Journal of Economics 109(4): 995-1025.

Shor, Boris. 1997. “What's Behind the Freedom House Ratings and Deliberations?" World Bank Transition: The Newsletter about Reforming Economies 8(3): 5 .

U.S. Central Intelligence Agency. Directorate of Intelligence. 1996. Handbook of International Economic Statistics 1996. Springfield, Va.: National Technical Information Service.

World Bank. 1996a. Statistical Handbook-States of the Former USSR. Washington.

- 1996b. World Development Report. Oxford University Press.

Zienkowski, Leszek. 1996. "The Polish Experience in Estimates of the Hidden Economy." Research Centre for Economic and Statistical Studies of the Central Statistical Office and the Polish Academy of Sciences Research Bulletin 5(1): 3-8. 